\title{
ELECTORAL UNCERTAINTY, FISCAL POLICY AND MACROECONOMIC FLUCTUATIONS
}

\author{
JIM MALLEY \\ Apostolis PHILIPPOPOULOS \\ ULRICH WOITEK
}

\begin{abstract}
CESIFO WORKING PAPER NO. 1593
CATEGory 5: Fiscal Policy, Macroeconomics AND Growth NOVEMBER 2005
\end{abstract}

An electronic version of the paper may be downloaded

- from the SSRN website:

www.SSRN.com

- from the CESifo website: www.CESifo-group.de 


\title{
ELECTORAL UNCERTAinTy, FisCAL POLICY AND MACROECONOMIC FLUCTUATIONS
}

\begin{abstract}
In this paper we study the link between elections, fiscal policy and aggregate fluctuations. The set-up is a stylized dynamic stochastic general equilibrium model incorporating both technology and political re-election shocks. The later are incorporated via a two-party model with elections. The main theoretical prediction is that forward-looking incumbents, with uncertain prospects of re-election, find it optimal to follow relatively shortsighted fiscal policies, and that this hurts capital accumulation. Our econometric estimation, using U.S. data, finds a statistically significant link between electoral uncertainty and policy instruments and in turn macroeconomic outcomes.
\end{abstract}

JEL Code: D9, E6, H1, H5.

Keywords: political uncertainty, business cycles \& growth, optimal policy, hybrid maximum likelihood estimation.

\author{
Jim Malley \\ Department of Macroeconomics \\ University of Stirling \\ Stirling FK9 4LA, Scotland \\ United Kingdom \\ j.r.malley@stir.ac.uk
}

Apostolis Philippopoulos

Department of International and European

Economic Studies

Athens University of Economics \& Business

76 Patission Street

Athens 10434

Greece

aphil@aueb.gr

\author{
Ulrich Woitek \\ Institute for Empirical Economics \\ University of Zurich \\ Winterthurerstr. 30 \\ 8006 Zurich \\ Switzerland \\ u.woitek@iew.unizh.ch
}

We would like to thank Peter Ireland, Hashmat Khan, Peter Sinclair, Raf Wouters and other seminar participants at the Bank of England workshop on "Estimated DSGE Models for Monetary Policy Analysis". We also thank George Economides, Simon Price and seminar participants at the Athens University of Economics \& Business; the Universities of Augsburg, Cyprus, Stirling and Vienna; and the ECFIN Research Conference on "Business Cycles and Growth in Europe” for helpful comments and suggestions. The usual disclaimer applies. 


\section{Introduction}

Modern business cycle theory treats growth and cycles as integrated phenomena that cannot be analyzed separately. It also suggests that both should arise as the equilibrium outcomes of rational optimizing private and public economic agents. As is well recognized, the reference model of this research program (known as real business cycle $(R B C)$ theory) is the standard neoclassical growth model augmented with technology shocks ${ }^{1}$. In recent years, there have been numerous developments that have attempted to improve the model's ability to reproduce both bi-variate and multi-variate correlations between key macroeconomic time series ${ }^{2}$. Two common features of all these extensions (known as dynamic stochastic general equilibrium (DSGE) models) are the inclusion of various demand and supply shocks, as well as the introduction of market frictions that affect the channels through which these impulses propagate through the economy.

An important branch of the DSGE literature has introduced fiscal policy into the basic setup ${ }^{3}$. A parsimonious way of achieving this is to model economic policy as the outcome of elections between alternating political parties (see e.g. Drazen (2000) and Persson and Tabellini (1999, 2000) for thorough surveys). A central result of these models (known as political business cycle $(P B C)$ models) is that uncertainty about remaining in office pushes incumbent politicians to follow relatively short-sighted policies and engineer electoral business cycles, which in turn result in inefficient macroeconomic outcomes $^{4}$.

The quantitative link between electoral uncertainty, endogenous changes in fiscal policy and the ensuing macroeconomic impacts is still an open issue. For instance, while there is some evidence of electoral effects on fiscal policy instruments, there is no evidence that this is translated into changes in the macroeconomy (see Alesina et al. (1997) and Drazen (2000)). More impor-

\footnotetext{
${ }^{1}$ For a critical review of the basic $R B C$ model, see e.g. King and Rebelo (1999).

${ }^{2}$ For the main extensions of the basic $R B C$ model, see e.g. the papers in the volume edited by Cooley (1995).

${ }^{3}$ For $D S G E$ models with exogenous fiscal policy, see e.g. Christiano and Eichenbaum (1992), Baxter and King (1993), McGrattan (1994), Gali (1994) and Baier and Glomm (2001). For DSGE models, where fiscal policy is chosen by a benevolent Ramsey government, see e.g. Lucas (1990), Chari et al. (1994), Lansing (1998) and Klein and Rios-Rull (2003).

${ }^{4}$ On the other hand, elections (or the fear of losing them) can work as a disciplinary device. For instance, they control the moral hazard of politicians, help voters to select the most competent politician, or help voters to select the policy-maker whose ideology is closer to their own. Here, following most of the related $P B C$ literature, we abstract from the benefits of electoral uncertainty.
} 
tantly, there seems to be a gap between the albeit parsimonious theoretical $P B C$ models and their econometric counterparts. In particular, with few notable exceptions ${ }^{5}$, existing empirical work has been only loosely guided by the theory. Typically these studies are based on simple autoregressive specifications in which various policy instruments and macroeconomic outcomes are regressed on own lagged values, political dummies and measures of socio-political instability.

In contrast, our research attempts to bridge the gap between $D S G E$ and $P B C$ models, as well as the gulf between the latter and the data. Our aim is to provide an integrated and tractable benchmark which improves our empirical understanding of how electoral uncertainty affects macroeconomic aggregates via the fiscal policy transmission mechanism. We also hope to shed some light into mounting post-war evidence in most OECD economies suggesting growing public sectors and secular changes in the composition of government expenditure in favor of public consumption at the expense of public investment ${ }^{6}$. To achieve these objectives we develop, estimate and simulate a $D S G E$ model whose theoretical and econometric foundations can be found in Barro (1990), Alesina and Tabellini (1990) and Ireland (2004).

Barro's (op cit.) model provides a framework in which public investment acts as the engine of growth. By adding government consumption to Barro's model, we have a simple setup capable of addressing policy-makers' key dilemma regarding whether to allocate scarce tax revenue to public consumption or investment. Moreover, the addition of a PBC model á la Alesina and Tabellini ( op cit.) provides a straightforward way in which policy-makers' choices are affected by electoral uncertainty. Since we also allow for endogenous re-election probabilities, these policy choices are further affected by the state of the economy. Finally, we follow the $R B C$ literature and incorporate technology shocks into our model, so that we can evaluate their importance relative to electoral shocks in generating observed patterns of changes in private and public spending. Given that the impacts of technology shocks are well understood, their inclusion provides a context in which to interpret our empirical findings regarding the transmission of, and effects of, electoral shocks.

To estimate the model, we use U.S. quarterly data from 1947:1 to 2004:2 and employ Ireland's (op cit.) econometric methodology to obtain the maximum likelihood estimates of the structural parameters, the coefficients of the stochastic processes driving electoral and technology shocks, as well as

\footnotetext{
${ }^{5}$ Examples of papers, which formally estimate theory-based $P B C$ models, include: Alesina and Sachs (1988) for a partisan model of monetary policy for the US; and Lockwood et al. (1996) for a public-finance model for the UK.

${ }^{6}$ See e.g. Tanzi and Schuknecht (2000) and the references cited therein.
} 
the parameters from a vector $A R(1)$ model of the measurement errors. Ireland's hybrid method, in contrast to earlier approaches (see e.g. Sargent (1989)), has the distinct advantage of allowing the statistical model of the "measurement errors" to account for movements and co-movements in the data which unavoidably cannot be captured by our, or indeed any, stylized $D S G E$ model.

Our main prediction is that electoral uncertainty pushes governments to follow relatively short-sighted fiscal policies and this is detrimental for the macro-economy. When there is electoral uncertainty and the political parties prefer to remain in office, they effectively face a "quasi-finite" time horizon" More specifically, the higher the electoral uncertainty, the more the incumbent party discounts the future. Accordingly, electoral uncertainty pushes rational forward-looking policymakers to opt for a larger size of the public sector and also spend more on non-productive activities relative to productive ones. The effects of these two policies work in the same direction by hurting private capital accumulation for the sake of higher current government consumption spending.

Our econometric results provide clear support for these propositions. By explicitly modeling the behavioral channel through which the election process affects the macroeconomy, we find statistically significant effects of electoral shocks on the policy instruments and the various components of output. In particular, there is evidence that shocks that increase electoral uncertainty lead to higher tax rates and less productive use of government spending. Qualitatively, positive popularity and technology shocks have similar beneficial effects on private spending (consumption and investment) and economic growth. Quantitatively, the effects on the policy instruments are dominated by electoral shocks, while private spending and economic growth (as expected) are affected more by technology than by electoral shocks. Finally our forecast error decompositions reveal that while political shocks dominate productivity shocks in the short-run, in the long-run, economic growth is what matters most for staying in office.

\section{Theoretical model}

In this section, we solve for the optimal decisions of households, firms and political parties. The (Markov-perfect) general equilibrium solution will consist of a system of dynamic relations, which jointly specify the paths of pri-

\footnotetext{
${ }^{7}$ The transmission mechanism is similar to that in e.g. Alesina and Tabellini (1990), Lockwood et al. (1996), Devereux and Wen (1998), Persson and Tabellini (1999) and Economides et al. (2003).
} 
vate consumption and investment; public consumption and investment; the income tax rate and the share of tax revenues allocated to government investment relative to government consumption. The solution will be in terms of the predetermined capital stock and the expected values of the exogenous stochastic variables which include innovations to technology and the re-election probability.

The setup will be a two-party variant of Barro's (op cit.) model of longterm growth and optimally chosen fiscal policy. In addition to having two political parties that alternate in power, the other difference from Barro's model is that we allow the incumbent party to choose not only the income tax rate but also the allocation of tax revenues between public investment and consumption $^{8}$. In this framework, elections take place in each period. The timing within a period is as follows: First, electoral uncertainty is resolved. Second, the elected party chooses current policy. Third, private agents act.

We deliberately employ a simple model. This applies especially to the private economy, since the presence of endogenous re-election probabilities will unavoidably complicate the policy process.

\subsection{Household's problem}

The representative household maximizes the following time-separable utility function

$$
E \sum_{t=0}^{\infty} \beta^{t} u\left(C_{t}, L_{t}, G_{t}^{c}\right)
$$

where $E$ is an expectations operator, and $C_{t}, L_{t}$, and $G_{t}^{c}$ are respectively private consumption, labor supply and government consumption at time $t$, $0<\beta<1$ is the rate of time preference and $u_{C_{t}}, u_{G_{t}^{c}}>0$ and $u_{L_{t}}<0$. The specific form for $u$ is given by

$$
u\left(C_{t}, L_{t}, G_{t}^{c}\right)=\ln C_{t}+\zeta \ln \left(1-L_{t}\right)+\delta \ln G_{t}^{c}
$$

where, $\zeta, \delta>0$ are the relative weights given to leisure, $\left(1-L_{t}\right)$ and public consumption respectively.

At time $t$, the household rents its predetermined capital, $K_{t}$, to the firm and receives $r_{t} K_{t}$, where $r_{t}$ is the market return to capital. It also supplies

\footnotetext{
${ }^{8}$ See Devereux and Wen (1998) and Economides et al. (2003) for Barro-type models incorporating electoral uncertainty. In these models however, the incumbent party only chooses the tax rate. See also Park and Philippopoulos (2003, 2004) for models in which the government chooses the allocation of tax revenues among public investment, public consumption and redistributive transfers.
} 
labor services, $L_{t}$, at a wage rate, $w_{t}$. Further, it receives dividends or profits made by firms, $\pi_{t}$. Thus, the household's budget constraint is given by

$$
K_{t+1}+C_{t}=\left(1-\tau_{t}\right)\left(r_{t} K_{t}+w L_{t}+\pi_{t}\right)
$$

where $K_{t+1}$ denotes the capital stock chosen at $t$ and $0<\tau_{t}<1$ is the income tax rate at $t$. For simplicity, we assume full capital depreciation (implying that the end-of-period capital stock is equal to investment). The initial stock, $K_{0}$, is given.

\section{$2.2 \quad$ Firm's problem}

The representative firm maximizes the usual profit, $\pi_{t}$, function

$$
\pi_{t}=Y_{t}-r_{t} K_{t}-w_{t} L_{t} .
$$

As in the literature introduced by Barro (op cit.), public services provide production externalities to private firms and technology at the firm's level takes a Cobb-Douglas form, e.g.

$$
Y_{t}=A_{t} K_{t}^{\alpha} L_{t}^{(1-\alpha)} G_{t}^{i(1-\alpha)}
$$

where is $Y_{t}$ output, $A_{t}$ is productivity, $G_{t}^{i}$ is public production services and $0<\alpha<1$ is the productivity of private capital. Following the $R B C$ literature we assume that the stochastic process determining $A_{t}$ is first-order Markov

$$
A_{t}=A_{0}^{\left(1-\rho_{a}\right)} A_{t-1}^{\rho_{a}} e^{\eta_{t}}
$$

where $A_{0}>0$ is a constant, $0<\rho_{a}<1$ is the autoregressive parameter and the innovations, $\eta_{t} \sim i i d\left(0, \sigma_{\eta}^{2}\right)$.

\subsection{Government budget constraint}

For simplicity we assume that the government runs a balanced budget, therefore

$$
G_{t}^{i}+G_{t}^{c}=\tau_{t}\left(r_{t} K_{t}+w_{t} L_{t}+\pi_{t}\right)
$$

Without loss of generality, we suppose that a share of total tax revenues, $0<\theta_{t}<1$, finances $G_{t}^{i}$ and the rest, $0<1-\theta_{t}<1$, finances $G_{t}^{c}$. Thus, (7) can be decomposed into:

$$
\begin{gathered}
G_{t}^{i}=\theta_{t} \tau_{t}\left(r_{t} K_{t}+w_{t} L_{t}+\pi_{t}\right) \\
G_{t}^{c}=\left(1-\theta_{t}\right) \tau_{t}\left(r_{t} K_{t}+w_{t} L_{t}+\pi_{t}\right)
\end{gathered}
$$

where inspection of (7)-(9) reveals that $\tau_{t}$ and $\theta_{t}$ fully summarize fiscal policy at time $t$. 


\subsection{Competitive decentralized equilibrium}

Given the paths of the economic policy instruments $\left\{\tau_{t}, \theta_{t}\right\}_{t=0}^{\infty}$, a competitive decentralized equilibrium $(C D E)$ is defined to be a sequence of allocations $\left\{C_{t}, L_{t}, K_{t+1}, G_{t}^{i}, G_{t}^{c}\right\}_{t=0}^{\infty}$ and prices $\left\{r_{t}, w_{t}\right\}_{t=0}^{\infty}$ such that: (i) households maximize (1) subject to (3) and firms maximize (4) subject to (5) by taking prices, tax policy and public services as given; (ii) all budget constraints are satisfied; (iii) all markets clear. Then, as Appendix A shows, we get (see also e.g. Sargent (1987) and McCallum (1989)):

Result 1: In a competitive decentralized equilibrium (for any feasible economic policy), optimal private consumption and capital accumulation are:

$$
\begin{gathered}
C_{t}=(1-\alpha \beta) A_{t}^{1 / \alpha}\left(1-\tau_{t}\right)\left(\tau_{t} \theta_{t} L_{t}\right)^{(1-\alpha) / \alpha} K_{t} \\
K_{t+1}=\alpha \beta A_{t}^{1 / \alpha}\left(1-\tau_{t}\right)\left(\tau_{t} \theta_{t} L_{t}\right)^{(1-\alpha) / \alpha} K_{t}
\end{gathered}
$$

where $L_{t} \equiv L=\frac{1-\alpha}{1-\alpha+\zeta(1-\alpha \beta)}$.

Moreover the solutions for the two types of public services in a CDE are:

$$
\begin{gathered}
G_{t}^{i}=\theta_{t} \tau_{t} A_{t}^{1 / \alpha}\left(\tau_{t} \theta_{t} L_{t}\right)^{(1-\alpha) / \alpha} K_{t} \\
G_{t}^{c}=\left(1-\theta_{t}\right) \tau_{t} A_{t}^{1 / \alpha}\left(\tau_{t} \theta_{t} L_{t}\right)^{(1-\alpha) / \alpha} K_{t} .
\end{gathered}
$$

Note that our model specification ${ }^{9}$ permits an exact closed-form solution. Also, $C_{t}$ and $K_{t+1}$ depend on the beginning-of-period capital stock and the current values of the policy instruments only, which will make the policymakers' optimization problem recursive (see below). However, before we move on to the policymakers' problem, further note two economic implications of the $C D E$. First, (11) gives the usual Laffer curve effect from the tax rate to the rate of economic growth. Thus, if $\left(1-\alpha-\tau_{t}\right)>0$, the growth rate increases with $\tau_{t}$ and if $\left(1-\alpha-\tau_{t}\right)<0$, the growth rate decreases with $\tau_{t}$ (see, Barro, (op cit.)). Second, (11) also implies that the growth rate increases monotonically with $\theta_{t}$. Thus, a higher share of tax revenues allocated to public investment relative to public consumption always stimulates growth.

Therefore the CDE solution, for any feasible policy, consists of equations (10)-(13) and (6) for $C_{t}, K_{t+1}, G_{t}^{i}, G_{t}^{c}$ and $A_{t}$ respectively. It is convenient for what follows to re-express the four components of output in stationary form by dividing (10)-(13) by the predetermined capital stock, $K_{t}{ }^{10}$. In effect

\footnotetext{
${ }^{9}$ That is, Cobb-Douglas functions for utility and production as well as full capital depreciation.

${ }^{10}$ Note that $K_{t} \equiv I_{t-1}$, which follows from our assumption of full capital depreciation.
} 
this removes a common stochastic trend from each of the control variables. Thus,

$$
\begin{gathered}
c_{t}=(1-\alpha \beta) A_{t}^{1 / \alpha}\left(1-\tau_{t}\right)\left(\tau_{t} \theta_{t} L_{t}\right)^{(1-\alpha) / \alpha} \\
i_{t}=\alpha \beta A_{t}^{1 / \alpha}\left(1-\tau_{t}\right)\left(\tau_{t} \theta_{t} L_{t}\right)^{(1-\alpha) / \alpha} \\
g_{t}^{i}=\theta_{t} \tau_{t} A_{t}^{1 / \alpha}\left(\tau_{t} \theta_{t} L_{t}\right)^{(1-\alpha) / \alpha} \\
g_{t}^{c}=\left(1-\theta_{t}\right) \tau_{t} A_{t}^{1 / \alpha}\left(\tau_{t} \theta_{t} L_{t}\right)^{(1-\alpha) / \alpha}
\end{gathered}
$$

where, $c_{t} \equiv C_{t} / K_{t}, i_{t} \equiv K_{t+1} / K_{t}, g_{t}^{i} \equiv G_{t}^{i} / K_{t}$, and $g_{t}^{c} \equiv G_{t}^{c} / K_{t}$.

\subsection{The electoral system, political parties and defini- tion of general equilibrium}

To endogenize economic policy, as summarized by $\tau_{t}$ and $\theta_{t}$ at each $t$, we consider a non-cooperative (Nash) game between two political parties, denoted by $h$ and $j$. The parties can alternate in power according to a stochastic reelection probability. Specifically, if elections take place in each time-period ${ }^{11}$, we assume that the party in power at $t$ has a probability of $0 \leq q_{t+1} \leq 1$ of winning the next election and remaining in power at $t+1$. Accordingly, $0 \leq\left(1-q_{t+1}\right) \leq 1$ is the incumbent's probability of losing the next election and being out of power at $t+1$.

We assume a state-dependent stochastic rule for $q_{t}$ of the form:

$$
q_{t+1}=q_{0}^{\left(1-\rho_{q}\right)} q_{t}^{\rho_{q}}\left(\frac{i_{t}}{i}\right)^{\gamma} e^{\varepsilon_{t+1}}
$$

where $0<q_{0}<1$ is a constant, $0<\rho_{q}<1$ is the autoregressive parameter, $i_{t} \equiv \frac{K_{t+1}}{K_{t}}$ is current capital accumulation (see equation $\left(11^{\prime}\right)$ above), $i$ is the model-consistent long-run value of $i_{t}$ (for any variable $x_{t}, x$ denotes its long-run value $)^{12}, \gamma \geq 0$ is a feedback parameter that measures the effect of the state of the economy on the re-election probability, and $\varepsilon_{t} \sim$ iid $\left(0, \sigma_{\varepsilon}^{2}\right)$

\footnotetext{
${ }^{11}$ See e.g. Lockwood et al. (1996) and Persson and Tabellini (2000) for models where elections take place every other period. This produces electoral cycles in the sense that preelection periods can differ from post-election periods. In our model electoral uncertainty affects the economy in the same way every period. Note that our main results do not depend on this assumption. Also note that we solve a general equilibrium dynamic multiperiod model, whereas Lockwood et al. have solved for the public finance sector only, and Persson and Tabellini have just studied two-period models.

${ }^{12}$ See Subsection 2.7 for discussion of how we derive the long-run solution.
} 
are the innovations to $q_{t}$. Note, the endogenous rule for $q_{t}$ has the desirable steady-state property that $q_{t}=q_{0}{ }^{13}$.

With $\gamma>0$, the incumbent's re-election probability increases with current capital accumulation. Obviously, there are other possible state variables that can affect the re-election probability. For instance, another obvious candidate in our model could be to employ the output gap, $\frac{y_{t}\left(\equiv Y_{t} / K_{t}\right)}{y}$. However, this argument has less intuitive properties than capital accumulation. For example, using capital accumulation in (14) implies: (i) a positive relationship between the re-election probability and the current share of tax revenues used to finance government investment, $\frac{\partial q_{t+1}}{\partial \theta_{t}}=\frac{\gamma(1-\alpha) q_{t+1}}{\alpha \theta_{t}}>0$; and (ii) a negative relationship between the re-election probability and the current income tax rate, $\frac{\partial q_{t+1}}{\partial \tau_{t}}=\frac{\gamma\left(1-\alpha-\tau_{t}\right) q_{t+1}}{\alpha \tau_{t}\left(1-\tau_{t}\right)}<0$ (when the income tax rate is higher than the productivity of public production services $)^{14}$. In contrast, if we employ the output gap in (14), then the probability of being re-elected increases when the income tax increases, i.e. $\frac{\partial q_{t+1}}{\partial \tau_{t}}=\frac{\gamma(1-\alpha) q_{t+1}}{\alpha \tau_{t}}>0$. Since this property is at odds with both politicians' observed behaviour or promises prior to an election as well as with voters' preferences, we prefer to endogenize $q$ by using capital accumulation as the state variable.

Given the above, the political general equilibrium is defined as follows. First, when in power at $t$, the elected party chooses policy during its term in office, $\tau_{t}$ and $\theta_{t}$, subject to the CDE summarized by (10)-(13). In doing so, it takes the future policy of the other party, which can be in power at $t+1$ with a nonzero probability $\left(1-q_{t+1}\right)$, as given. Second, we solve for Markov policy strategies, which means that $\tau_{t}$ and $\theta_{t}$ can be functions of the current value of the state variables only. Moreover, we will focus on symmetric Markov strategies so that the parties' policies will be alike ex post ${ }^{15}$.

\subsection{Fiscal policies and political general equilibrium}

From the political parties' viewpoint, the state variables at $t$ are the economy's inherited capital stock, $K_{t}$, and the current value of the stochastic

\footnotetext{
${ }^{13}$ We include a constant, $q_{0}$, since otherwise the mean of $q_{t}$ would be zero, which is counter intuitive in the case of re-election probabilities. Also note that the autoregressive component of (14) is consistent with previous empirical studies. For instance, Dixit et al. (2000) use an exogenous political process similar to that in (14), and provide empirical support. In addition, when Price and Sanders (1994) examine the determinants of government popularity in post-war Britain, they find evidence of substantial history-dependence in popularity.

${ }^{14}$ We show below that, along the optimal path, this is indeed the case.

${ }^{15}$ Thus, the model highlights electoral and not partisan effects on growth. This appears reasonable in light of the findings of Alesina et al. (op cit.) who do not find any systematic partisan effects on growth.
} 
processes for $q_{t}$ and $A_{t}$. Therefore, let $V^{P_{h}}\left(K_{t} ; q_{t}, A_{t}\right)$ and $V^{N_{h}}\left(K_{t} ; q_{t}, A_{t}\right)$ denote the value functions of party $h$ at time $t$ when in power and when out of power respectively. Party $j$ 's problem is symmetric. These two value functions must satisfy the following pair of Bellman equations for each party ${ }^{16}$ :

$$
\begin{aligned}
V^{P_{h}}\left(K_{t} ; q_{t}, A_{t}\right)= & \max _{\tau_{t}^{h}, \theta_{t}^{h}}\left\{R+\ln C_{t}+\delta \ln G_{t}^{c}+\beta E_{t}\left[q_{t+1} V^{P_{h}}\left(K_{t+1} ; q_{t+1}, A_{t+1}\right)\right.\right. \\
& \left.\left.+\left(1-q_{t+1}\right) V^{N_{h}}\left(K_{t+1} ; q_{t+1}, A_{t+1}\right)\right]\right\} \\
V^{N_{h}}\left(K_{t} ; q_{t}, A_{t}\right)= & \ln C_{t}+\delta \ln G_{t}^{c}+\beta E_{t}\left[\left(1-q_{t+1}\right) V^{P_{h}}\left(K_{t+1} ; q_{t+1}, A_{t+1}\right)\right. \\
& \left.+q_{t+1} V^{N_{h}}\left(K_{t+1} ; q_{t+1}, A_{t+1}\right)\right]
\end{aligned}
$$

where $C_{t}, K_{t+1}, G_{t}^{c}$ and $q_{t+1}$ are given by (10), (11), (13) and (14) respectively and the parameter $R \geq 0$ is an exogenous extra rent when in power. Party $j \neq h$ solves an analogous problem, so that we have two pairs of value functions like (15) and (16).

Note the following considerations regarding the set-up of the Bellman equations. First, since $L_{t} \equiv L$ in a $C D E$, we do not include $\zeta \ln \left(1-L_{t}\right)$ in the party's objective functions. Second, in (15), the incumbent has a probability $q_{t+1}$ of remaining in power, and a probability $\left(1-q_{t+1}\right)$ of losing the coming election. By contrast, in (16), when the party is out of power it knows that there is a probability $q_{t+1}$ of continuing to be out of power and a probability $\left(1-q_{t+1}\right)$ of returning to power in the next election. Third, the exogenous ego rents when in power, $R \geq 0$, "reflect the value attached to winning the election and holding office" (see Persson and Tabellini, 2000, pp. 49-50). In contrast, when out of power, the party's instantaneous payoff is only the representative citizen's, i.e. $\ln C_{t}+\delta \ln G^{17}$. Fourth, in (15), the policy instruments are chosen by the incumbent party $h$. By contrast, in (16), the policy instruments are those of party $j$ since party $h$ is out of power. For instance, in (15) $K_{t+1}=\alpha \beta A_{t}^{1 / \alpha}\left(1-\tau_{t}^{h}\right)\left(\tau_{t}^{h} \theta_{t}^{h} L_{t}\right)^{(1-\alpha) / \alpha} K_{t}$ since party $h$ has been in power at $t$, while in (16) $K_{t+1}=\alpha \beta A_{t}^{1 / \alpha}\left(1-\tau_{t}^{j}\right)\left(\tau_{t}^{j} \theta_{t}^{j} L_{t}\right)^{(1-\alpha) / \alpha} K_{t}$ since it is party $j$ that has been in power at $t$. In other words, when party $h$ solves the dynamic programming problem in (15)-(16), it takes $\tau_{t}^{j}$ and $\theta_{t}^{j}$ in (16) as given. This justifies the Nash setup between parties $h$ and $j$. Moreover, policies will be symmetric ex post. Fifth, the structure of the political optimization problem is recursive. In other words, given the

\footnotetext{
${ }^{16}$ See e.g. Alesina and Tabillini (op cit.) for similar modeling.

${ }^{17}$ This is a popular and convenient way to differentiate "in" from "out" of power payoffs (see various models in the book by Persson and Tabellini, op cit.). See also Lockwood et al. (op cit.) who provide references from the political science literature that support our approach.
} 
other party's policy choices, current policy choices affect returns dated at $t, t+1, \ldots \infty$ (see e.g. Sargent (1987)). Hence, optimal polices will be timeconsistent.

Since exact analytical solutions cannot be obtained from the optimization problem given by (15)-(16), we use first-order log-linear approximations around the long-run equilibrium ${ }^{18}$. This will enable us to obtain an approximate closed-form analytical solution for the policy instruments $\tau_{t}$ and $\theta_{t}$. We conjecture that $V^{P_{h}}\left(K_{t} ; q_{t}, A_{t}\right)=u_{0}^{P_{h}}+u_{1}^{P_{h}} \ln K_{t}+u_{2}^{P_{h}} \ln q_{t}+u_{3}^{P_{h}} \ln A_{t}$ and $V^{N_{h}}\left(K_{t} ; q_{t}, A_{t}\right)=u_{0}^{N_{h}}+u_{1}^{N_{h}} \ln K_{t}+u_{2}^{N_{h}} \ln q_{t}+u_{3}^{N_{h}} \ln A_{t}$ can approximately solve the problem of party $h$ in (15)-(16), where the $u$ 's are undertermined coefficients as defined in Appendix B. There are analogous conjectures for party $j \neq h$. Appendix B shows that if we use these conjectures into (15)(16), differentiate the right-hand side of (15) with respect to the controls $\tau_{t}^{h}$ and $\theta_{t}^{h}$, impose the ex post symmetry conditions $\tau_{t}^{h}=\tau_{t}^{j} \equiv \tau_{t}, \theta_{t}^{h}=\theta_{t}^{j} \equiv \theta_{t}$, $u^{P_{h}}=u^{P_{j}} \equiv u^{P}$ and $u^{N_{h}}=u^{N_{j}} \equiv u^{N}$, and take a first-order linear approximation around the model-consistent long-run equilibrium presented below, we obtain:

Result 2: In a Markov-perfect general equilibrium of a symmetric Nash game between the political parties, the income tax rate, $\tau_{t}$, and the share of total tax revenues used to finance government investment, $\theta_{t}$, are approximately given by:

$$
\begin{aligned}
& \widehat{\tau}_{t}=\Omega_{5}\left(\rho_{q} \widehat{q}_{t}+\frac{\gamma}{\alpha} \widehat{A}_{t}\right) \\
& \widehat{\theta}_{t}=\Omega_{6}\left(\rho_{q} \widehat{q}_{t}+\frac{\gamma}{\alpha} \widehat{A}_{t}\right)
\end{aligned}
$$

where for any variable $x_{t}, x_{t} \equiv \frac{x_{t}-x}{x} \cong \ln \left(x_{t} / x\right) ; x$ is the model-consistent long-run value of $x_{t}$;

$$
\begin{array}{ll}
\Omega_{1} \equiv \frac{\delta[\tau(\tau+\alpha-1)+(1-\alpha)(1-\tau)]}{(\tau+\alpha-1)}+\delta(1-\tau)-(1-\alpha-\tau)^{2}\left(M+\frac{\beta^{2} \gamma R}{(1-\beta)}\right) \frac{\gamma q}{\alpha(1-\tau)} ; \\
\Omega_{2} \equiv(1-\alpha-\tau)\left(M+\frac{\beta^{2} \gamma R}{(1-\beta)}\right) q ; & \Omega_{3} \equiv \frac{\delta}{(1-\theta)^{2}}-\frac{(1-\alpha)^{2}}{\alpha^{2} \theta}\left(M+\frac{\beta^{2} \gamma R}{(1-\beta)}\right) \gamma q ; \\
\Omega_{4} \equiv \frac{(1-\alpha)}{\alpha \theta}\left(M+\frac{\beta^{2} \gamma R}{(1-\beta)}\right) q ; & \Omega_{5} \equiv \frac{\Omega_{2}}{\Omega_{1}}\left(1+\frac{\gamma(1-\alpha) \Omega_{5}}{\alpha}\right) ; \\
\Omega_{6} \equiv \frac{\Omega_{4}\left(1+\frac{\gamma(1-\alpha-\tau)}{\alpha(1-\tau)} \frac{\Omega_{2}}{\Omega_{1}}\right)}{\Omega_{3}-\frac{\gamma^{2}(1-\alpha-\tau)(1-\alpha)}{\alpha_{2}^{2}(1-\tau)} \frac{\Omega_{2} \Omega_{4}}{\Omega_{1}}} & \Omega_{7} \equiv \rho\left(1+\frac{\gamma(1-\alpha) \Omega_{5}}{\alpha}+\frac{\gamma(1-\alpha-\tau) \Omega_{6}}{\alpha(1-\tau)}\right) ; \\
\text { and } M \equiv \beta \gamma\left(\frac{\Omega_{7} 2 \beta^{2} R q}{(1-\beta)\left[1+\Omega_{7} \beta(1-2 q)\right]}\right) . &
\end{array}
$$

\footnotetext{
${ }^{18}$ Campbell and Viceira (2002, ch. 5) use a similar type of approximation to solve the Bellman equation in dynamic asset pricing models. This is the same type of approximation used in e.g. Campbell (1993), but instead of using it to linearize the budget constraint, here we use it to solve the Bellman equation. Details are in Appendix B.
} 
Therefore, (17)-(18), jointly with the CDE in $\left(10^{\prime}\right)-\left(13^{\prime}\right)$, give a stationary political general equilibrium in which economic policy is optimally chosen by two political parties that alternate in power according to the re-election probability in (14). The solution is summarized in the next subsection, and its quantitative economic implications will be studied post econometric estimation using impulse response functions and forecast error decompositions. At this stage, we just note that although we allowed the policy instruments to depend also on the predetermined capital stock, $K_{t}$, in (15)-(16), the policy instruments are eventually independent of $\widehat{K}_{t}$, in (17)-(18). This is a type of tax smoothing result, as in the model introduced by Barro (1999), in the sense that policymakers find it efficient not to respond to the capital stock when they set policy.

\subsection{The steady-state and the linearized political gen- eral equilibrium}

In the absence of technology and electoral shocks, i.e. $\eta_{t}=\varepsilon_{t}=0$ for all $t$, the economy converges to its steady-state in which all of the stationary variables are constant (for any $x_{t}, x$ denotes its long-run value).

Expressions for the model consistent long-run values of $A, c, i, g^{i}, g^{c}$ and $q$ being comprised of non-linear convolutions of the underlying structural parameters are obtained by suppressing the time subscripts in $(6),\left(10^{\prime}\right)-\left(13^{\prime}\right)$ and (14) respectively, and performing the appropriate recursive substitutions. Note that $A=A_{0}$, and $q=q_{0}$.

Appendix $\mathrm{C}$ shows that the long-run values of the policy instruments are $\tau=\frac{1+\delta-\alpha(1+\beta \delta)}{1+\delta}$ and $\theta=\frac{(1-\alpha)(1+\delta)}{1+\delta-\alpha(1+\beta \delta)}$. It is straightforward to show that this long-run solution coincides with the solution of a benevolent single government. The latter of course would not only hold in the long-run but for all $t$. Thus, in the long-run equilibrium, electoral uncertainty should not affect the conduct of policy. Also note that when agents do not value public consumption services (i.e. $\delta=0$ ), we obtain $\tau=1-\alpha$ and $\theta=1$ which is Barro's (1990) popular result for the optimal flat tax rate in a model with a single benevolent government.

We can now present the first-order Taylor series approximation of the stationary DSGE model around its steady state, e.g.

$$
\begin{aligned}
& \widehat{c}_{t}=\frac{1}{\alpha} \widehat{A}_{t}+\frac{(1-\alpha-\tau)}{\alpha(1-\tau)} \widehat{\tau}_{t}+\frac{(1-\alpha)}{\alpha} \widehat{\theta}_{t} \\
& \widehat{i}_{t}=\frac{1}{\alpha} \widehat{A}_{t}+\frac{(1-\alpha-\tau)}{\alpha(1-\tau)} \widehat{\tau}_{t}+\frac{(1-\alpha)}{\alpha} \widehat{\theta}_{t}
\end{aligned}
$$




$$
\begin{gathered}
\widehat{g}_{t}^{i}=\frac{1}{\alpha} \widehat{A}_{t}+\frac{1}{\alpha} \widehat{\tau}_{t}+\frac{1}{\alpha} \widehat{\theta}_{t} \\
\widehat{g}_{t}^{c}=\frac{1}{\alpha} \widehat{A}_{t}+\frac{1}{\alpha} \widehat{\tau}_{t}+\frac{(1-\alpha-\theta)}{\alpha(1-\theta)} \widehat{\theta}_{t} \\
\widehat{\tau}_{t}=\Omega_{5}\left(\rho_{q} \widehat{q}_{t}+\frac{\gamma}{\alpha} \widehat{A}_{t}\right) \\
\widehat{\theta}_{t}=\Omega_{6}\left(\rho_{q} \widehat{q}_{t}+\frac{\gamma}{\alpha} \widehat{A}_{t}\right) \\
\widehat{A}_{t}=\rho_{a} \widehat{A}_{t-1}+\eta_{t} \\
\widehat{q}_{t}=\rho_{q} \widehat{q}_{t-1}+\gamma\left[\frac{1}{\alpha} \widehat{A}_{t-1}+\frac{(1-\alpha-\tau)}{\alpha(1-\tau)} \widehat{\tau}_{t-1}+\frac{(1-\alpha)}{\alpha} \widehat{\theta}_{t-1}\right]+\varepsilon_{t} .
\end{gathered}
$$

where equations $\left(17^{\prime}\right)$ and $\left(18^{\prime}\right)$ are simply equations (17) and (18) rewritten, equations $\left(10^{\prime \prime}\right)-\left(13^{\prime \prime}\right),\left(6^{\prime \prime}\right),\left(14^{\prime \prime}\right)$ are the linearized versions of $\left(10^{\prime}\right)-$ $\left(13^{\prime}\right)$, (6) and (14) respectively, and $\Omega_{5}$ and $\Omega_{6}$ are defined in Section 2.6. This is the model we will estimate below.

\section{Econometric model}

In this section, we econometrically estimate our DSGE model using U.S. quarterly data from 1947:1 to 2004:2. To this end, we employ Ireland's ( op cit.) methodology which uses the Kalman Filter to obtain the maximum likelihood estimates of: (i) the underlying "deep" or structural parameters; (ii) the coefficients and variances of the processes driving electoral uncertainty and technology; (iii) and the parameters, variances and covariances from a vector $A R(1)$ model of the "measurement errors". In addition to providing estimates of the model's structural parameters, this section will present forecast accuracy comparisons with an unrestricted vector autoregressive model, parameter stability tests, impulse responses to political and productivity shocks and finally forecast error decompositions.

\subsection{Measurement Issues and the Data}

To numerically examine the quantitative implications of our DSGE model, we nominally require data for the four subcomponents of output: $\left(c_{t}, i_{t}, g_{t}^{i}, g_{t}^{c}\right)$, the two policy instruments: $\left(\tau_{t}, \theta_{t}\right)$, and the two stochastic exogenous processes: $\left(A_{t}, q_{t}\right)$. However, in practice, measured analogues of these data are either subject to observation error or are unobservable. For example, since the reported data on electoral uncertainty embody multiple dimensions of political uncertainty and instability, which make it different from the measure implied 
by our model (i.e. the "probability of staying in office"), we need to formally account for this additional error. Measurement errors are also particularly relevant when it comes to the distinction between government consumption and production services. Typically, national income accounting practice fails to recognize the investment characteristics of many categories of government expenditure. Examples include expenditure on education, or expenditure on social security programs ${ }^{19}$. Given the serious difficulties with obtaining an even loose correspondence between $\tau_{t}$ and $\theta_{t}$ and the available data, we treat these data as unobservables in the econometric analysis. The same reasoning applies to $A_{t}$ since, although estimates are available via growth accounting exercises, they would have to be generated using an alternative model to the one derived here. With these considerations in mind, we treat all of the control variables $\left(c_{t}, i_{t}, g_{t}^{i}, g_{t}^{c}\right)$ plus our measure of political uncertainty $q_{t}$ as being observable but with error, while our policy variables $\left(\tau_{t}, \theta_{t}\right)$ plus $A_{t}$ are treated as unobservable.

In the econometric estimation reported below, we employ U.S. data for real personal consumption expenditure, real gross private domestic investment and real government consumption expenditures \& gross investment taken from the Federal Reserve Bank of St. Louis's FRED database ${ }^{20}$. These three series are re-expressed in per capita terms by dividing by the mid-period population figures made available from the Bureau of Economic Analysis ${ }^{21}$. Finally our measure of electoral uncertainty is the presidential job approval rating collected by the Gallup Organization. These data are reported on a bi-weekly frequency in units of \% approval out of 100 which we convert to a quarterly frequency for the entire observation period ${ }^{22}$. Both the approval rate and the log deviation from its sample mean are summarized in Table 1. The measures of central tendency for the approval rating which are roughly $50 \%$ reflect, as expected, that a significant incumbency advantage or disadvantage does not exist over this long time span of data.

\footnotetext{
${ }^{19}$ This is widely recognized in the literature (see e.g. Devarajan et al. (1996) and Kneller et al., (1999)).

${ }^{20}$ The source data agency is the U.S. Department of Commerce: Bureau of Economic Analysis. All three series are seasonally adjusted at annual rate and are in billions of chained 2000 dollars. The FRED database can be found at: http://research.stlouisfed.org/fred2/

${ }^{21}$ More specifically, these data are taken from line 38 of Table 2.1. Personal Income and Its Disposition and are reported in units of 1000 . These data can be found at http://www.bea.doc.gov/.

${ }^{22}$ This information is compiled and made available by the Roper Center for Public Opinion Research, see http://roperweb.ropercenter.uconn.edu.
} 
Table 1: Presidential Approval Rating

\begin{tabular}{lcc}
\hline \hline & \% of 100 & \%dev. \\
\hline Mean & 54.97 & -0.029 \\
Median & 55.75 & 0.014 \\
Maximum & 87.00 & 0.459 \\
Minimum & 22.67 & -0.886 \\
Std. dev. & 12.43 & 0.249 \\
Obs. & 230 & 230 \\
\hline
\end{tabular}

\subsection{State-Space Representation}

As discussed above, our state $\left(A_{t}, q_{t}\right)$, control $\left(c_{t}, i_{t}, g_{t}^{i}, g_{t}^{c}\right)$ and policy $\left(\tau_{t}, \theta_{t}\right)$ variables are either measured with error or are unobservable. Accordingly, we will estimate our model's state-space representation using the Kalman Filter which is ideally suited for this purpose. For what follows it is useful to rewrite the log-linear model defined in Section 2.7 in matrix form, e.g.

$$
\begin{aligned}
& \mathbf{B} \boldsymbol{\alpha}_{t}=\mathbf{C} \boldsymbol{\alpha}_{t-1}+\mathbf{D} \boldsymbol{v}_{t} \\
& \mathbf{B}=\left(\begin{array}{cccccccc}
1 & 0 & 0 & 0 & -\widetilde{a} & -\widetilde{b} & -\widetilde{c} & 0 \\
0 & 1 & 0 & 0 & -\widetilde{a} & -\widetilde{b} & -\widetilde{c} & 0 \\
0 & 0 & 1 & 0 & -\widetilde{c} & -\widetilde{c} & -\widetilde{c} & 0 \\
0 & 0 & 0 & 1 & -\widetilde{c} & -\widetilde{d} & -\widetilde{c} & 0 \\
0 & 0 & 0 & 0 & 1 & 0 & -\widetilde{e} & -\widetilde{f} \\
0 & 0 & 0 & 0 & 0 & 1 & -\widetilde{g} & -\widetilde{h} \\
0 & 0 & 0 & 0 & 0 & 0 & 1 & 0 \\
0 & 0 & 0 & 0 & 0 & 0 & 0 & 1
\end{array}\right) ; \boldsymbol{\alpha}_{t}=\left(\begin{array}{c}
\widehat{c}_{t} \\
\widehat{i}_{t} \\
\widehat{g}_{t}^{i} \\
\widehat{g}_{t}^{c} \\
\widehat{\tau}_{t} \\
\widehat{\theta}_{t} \\
\widehat{A}_{t} \\
\widehat{q}_{t}
\end{array}\right) ; \\
& \mathbf{C}=\left(\begin{array}{cccccccc}
0 & 0_{6 x 8} & & & \\
0 & 0 & 0 & 0 & 0 & 0 & \rho_{a} & 0 \\
0 & 0 & 0 & 0 & \widetilde{i} & \widetilde{j} & \widetilde{k} & \rho_{q}
\end{array}\right) \\
& \mathbf{D}=\left(\begin{array}{c}
0_{6 x 2} \\
\mathbf{I}_{2 x 2}
\end{array}\right) ; \boldsymbol{v}_{t}=\left(\begin{array}{c}
\eta_{t} \\
\varepsilon_{t}
\end{array}\right) ; \widetilde{a}=\frac{(1-\alpha-\tau)}{\alpha(1-\tau)} ; \widetilde{b}=\frac{(1-\alpha)}{\alpha} ; \\
& \widetilde{c}=\frac{1}{\alpha} ; \widetilde{d}=\frac{(1-\alpha-\theta)}{\alpha(1-\theta)} ; \widetilde{e}=\Omega_{5} \frac{\gamma}{\alpha} ; \tilde{f}=\Omega_{5} \rho_{q} ; \widetilde{g}=\Omega_{6} \frac{\gamma}{\alpha} ; \\
& \widetilde{h}=\Omega_{6} \rho_{q} ; \widetilde{i}=\gamma \widetilde{a} ; \widetilde{j}=\gamma \widetilde{b} \text {; and } \widetilde{k}=\gamma \widetilde{c} \text {. }
\end{aligned}
$$

where $\Omega_{5}$ and $\Omega_{6}$ are defined in Section 2.6. Note that the presence of $\Omega_{5}$ and $\Omega_{6}$ requires that we respect all of the non-linear cross- and withinequations restrictions listed under equations (17)-(18). 
If we next formalize the distinction between variables observed with er$\operatorname{ror}^{23}$ and unobservables set out above, we can rewrite the above log-deviations model in state-space form:

$$
\begin{gathered}
\boldsymbol{\alpha}_{t}=\mathbf{T} \boldsymbol{\alpha}_{t-1}+\mathbf{R} \boldsymbol{v}_{t} \\
\mathbf{y}_{t}=\mathbf{Z} \boldsymbol{\alpha}_{t}+\boldsymbol{\nu}_{t} \\
\boldsymbol{\nu}_{t}=\mathbf{V} \boldsymbol{\nu}_{t-1}+\boldsymbol{\varsigma}_{t}
\end{gathered}
$$

where $\boldsymbol{\alpha}_{t}$ is the state or transition equation containing the unobservables; $\mathbf{T}=\mathbf{B}^{-\mathbf{1}} \mathbf{C} ; \mathbf{R}=\mathbf{B}^{-\mathbf{1}} \mathbf{D} ; \mathbf{y}_{t}$ is the measurement equation comprised of the observable variables; the system matrix $\mathbf{Z}$ links the unobservables to the observables; $\boldsymbol{\nu}_{t}$ is a vector of measurement errors which follow a vector $A R(1)$ process and $\boldsymbol{\varsigma}_{t} \sim N\left(\mathbf{0}, \mathbf{Q}_{\boldsymbol{\varsigma}}\right)$ are the the white noise errors, (see, Ireland (op cit.)). Further note that we re-express $\left(c_{t}^{*}, i_{t}^{*}, g_{t}^{i *}, g_{t}^{c *}\right)$ as a weighted sum to determine output deviations, i.e. $\widehat{y}_{t}^{*}=\frac{c}{y} \widehat{c}_{t}^{*}+\frac{i}{y} \widehat{i}_{t}^{*}+\frac{g^{i}}{y} \widehat{g}_{t}^{i *}+\frac{g^{c}}{y} \widehat{g}_{t}^{c *}$ and $y=$ $c+i+g^{i}+c^{g}$, e.g.

$$
\underbrace{\left(\begin{array}{c}
\widehat{y}_{t}^{*} \\
\widehat{q}_{t}^{*}
\end{array}\right)}_{\mathbf{y}_{t}}=\underbrace{\left(\begin{array}{cccccccc}
\frac{c}{y} & \frac{i}{y} & \frac{g^{i}}{y} & \frac{g^{c}}{y} & 0 & 0 & 0 & 0 \\
0 & 0 & 0 & 0 & 0 & 0 & 0 & 1
\end{array}\right)}_{\mathbf{Z}} \boldsymbol{\alpha}_{t}+\underbrace{\left(\begin{array}{c}
\nu_{1 t} \\
\nu_{2 t}
\end{array}\right)}_{\boldsymbol{\nu}_{t}} .
$$

Finally the measurement and transition equations respectively can be written more succinctly as follows

$$
\begin{gathered}
\mathbf{y}_{t}=\underbrace{\left(\begin{array}{ll}
\mathbf{Z} & \mathbf{I}_{2 x 2}
\end{array}\right)}_{\widetilde{\mathbf{Z}}} \underbrace{\left(\begin{array}{c}
\boldsymbol{\alpha}_{t} \\
\boldsymbol{\nu}_{t}
\end{array}\right)}_{\widetilde{\boldsymbol{\alpha}}_{t}} \\
\underbrace{\left(\begin{array}{c}
\boldsymbol{\alpha}_{t} \\
\boldsymbol{\nu}_{t}
\end{array}\right)}_{\widetilde{\boldsymbol{\alpha}}_{t}}=\underbrace{\left(\begin{array}{cc}
\mathbf{T} & 0_{8 x 2} \\
0_{8 x 2} & \mathbf{V}
\end{array}\right)}_{\widetilde{\mathbf{T}}} \underbrace{\left(\begin{array}{c}
\boldsymbol{\alpha}_{t-1} \\
\boldsymbol{\nu}_{t-1}
\end{array}\right)}_{\widetilde{\boldsymbol{\alpha}}_{t-1}}+\underbrace{\left(\begin{array}{cc}
\mathbf{R} & 0_{8 x 2} \\
0_{2 x 2} & \mathbf{I}
\end{array}\right)\left(\begin{array}{c}
\eta_{t} \\
\varepsilon_{t}
\end{array}\right)}_{\widetilde{\boldsymbol{v}}_{t}} .
\end{gathered}
$$

At time $t=1, \ldots, T$, the Kalman filter provides the optimal estimate for the state vector $\widetilde{\boldsymbol{\alpha}}_{t}$. The joint density function of the $T$ vectors of observations is given by

$$
\ln L(\mathbf{y}, \boldsymbol{\psi})=\prod_{t=1}^{N} p\left(\mathbf{y}_{t} \mid \mathbf{Y}_{t-1}\right)
$$

\footnotetext{
${ }^{23}$ For each observed or measured variable $X_{t}^{*}$ in our model, $X_{t}^{*}=X_{t}+\nu_{t}$ where $X_{t}$ is the true unobserved variable and $\nu_{t}$ is the measurement error.
} 
where $\boldsymbol{\psi}$ is a vector of hyperparameters and $p\left(\mathbf{y}_{t} \mid \mathbf{Y}_{t-1}\right)$ is the distribution of $\mathbf{y}_{t}$, conditional on the information set, $\mathbf{Y}$, at time $t-1$. The vector $\boldsymbol{\psi}$ includes: (i) the structural parameters, $\{\alpha, \beta, \gamma, \delta, \zeta, R\}$; (ii) the long-run values of productivity and the election probability, $\{A, q\}$; (iii) the firstorder autoregressive parameters and the error variances for $A_{t}$ and $q_{t},\left\{\rho_{a}\right.$, $\left.\rho_{q}\right\},\left\{\sigma_{a}^{2}, \sigma_{q}^{2}\right\}$; (iv) the parameters for the $V A R(1)$ process describing the measurement errors, $\left\{\nu_{11}, \nu_{12}, \nu_{21}, \nu_{22}\right\}$; and (v) the error variances and covariance for the $\widehat{y}_{t}^{*}$ and $\widehat{q}_{t}^{*}$ measurement equations, $\left\{\sigma_{\widehat{y}^{*}}^{2}, \sigma_{\widehat{q}^{*}}^{2}, \sigma_{\widehat{y}^{*} \widehat{q}^{*}}^{2}\right\}$. Given the information set $\mathbf{Y}_{t-1}$, the true state vector is normally distributed with mean $\mathbf{a}_{t}$ and covariance matrix $\mathbf{P}_{t}$. Hence, $\mathbf{y}_{t}$ is also normally distributed with mean $\mathbf{y}_{t \mid t-1}=\widetilde{\mathbf{Z}}_{t} \mathbf{a}_{t \mid t-1}$ and error covariance matrix $\mathbf{F}_{t}$. Accordingly the log likelihood function is

$$
\ln L(\mathbf{y}, \boldsymbol{\psi})=-\frac{n T}{2} \ln 2 \pi-\frac{1}{2} \sum_{t=1}^{T} \ln \left|\mathbf{F}_{t}\right|-\frac{1}{2} \sum_{t=1}^{T} \widetilde{\boldsymbol{v}}_{t}^{\prime} \mathbf{F}_{t} \widetilde{\boldsymbol{v}}_{t}
$$

which has to be maximized with respect to the vector $\boldsymbol{\psi}$ and $n$ is the number of measurement equations.

\subsection{Results}

In this section we first report the full sample estimates of our 19 hyperparameters and their standard errors. Second, we conduct $S$-tests (see Diebold and Mariano (1995) and Harvey et al. (1997)) to evaluate the null hypothesis that there is no difference between the $k$-step ahead forecast accuracy of our $D S G E$ model and a benchmark unrestricted vector autoregression $(U V A R)$. We also undertake stability testing of our parameter estimates over several sub-samples to test for parameter constancy. Third, after we have established these model properties, we conduct an innovation accounting exercise to establish the relative quantitative implications of electoral uncertainty and technological change on the macro-economy.

\subsubsection{Parameter Estimates}

The full sample parameter estimates and standard errors reported in Table 2 below were obtained in a manner consistent with our priors which were naturally very diffuse with respect to the variances and covariances ${ }^{24}$. However,

\footnotetext{
${ }^{24}$ Except of course that the variances must be positive. To ensure that the covariance matrix is positive semidefinite, we feed the elements of a Cholesky decomposition as hyperparameters, and transform it back when building the system matrices of the state space system (see e.g. Harvey, 1989, p.109)
} 
based on constraints dictated by the theory in Section 2, we do have strong priors regarding the structural parameters. For the discussion which follows we will denote the vector of 8 structural parameters as $\boldsymbol{\pi}^{s}$ and elements of this vector as $\pi_{i}^{s}$. Recall that these 8 parameters include the productivity of private capital, $\alpha$, where $(1-\alpha)$ is the productivity of public capital; the subjective rate of time preference, $\beta$; the weights consumers place on government consumption and leisure relative to private consumption in their utility function, i.e. $\delta$ and $\zeta$ respectively; the state dependent feedback parameter determining the re-election probability, $\gamma$; the long-run value of productivity, $A$; the long-run re-election probability, $q$; and the extra rents accruing to party's in power, $R$. To encompass the range of values found in other empirical and calibration studies, we impose the following restrictions in our estimation: $0.3<\alpha<0.75 ; 0.95<\beta<0.99 ; 0<\gamma<0.5 ; 0<\delta<1$; $1<\zeta<4 ; R>0 ; 0<A<6$; and $0<q<1$ (see, e.g. Baier and Glomm (2001), Lansing (1998), and Barro and Sala-i-Martin (2004), Chari et al. (1994, 1995), McGrattan (1994), Aschauer (1989), Barro (1989)).

To formally incorporate this non-sample information, we apply several transformations to each of the structural parameters prior maximizing the likelihood function. Following Ireland ( op cit.), the first of these has the effect of restricting each transformed parameter to lie between zero and unity; e.g. $\pi_{i}^{t_{1}} \in(0,1) \rightarrow \pi_{i}^{t_{1}}=\sqrt{\frac{\left(\pi_{i}^{s}\right)^{2}}{1+\left(\pi_{i}^{s}\right)^{2}}}$. Given the high degree of non-linearity in the likelihood function and in the convolutions of structural parameters, which must also satisfy both within- and cross-equation restrictions, to improve the numerical properties of our estimation, we further transform $\pi_{i}^{t_{1}}$ using the ranges listed above. This helps us to avoid conditioning on fixed parameter values which are unreasonable in wider intervals. The additional transformation is placed on $\pi_{i}^{t_{1}}$, e.g. $\pi_{i}^{t_{2}} \in(a, b) \rightarrow \pi_{i}^{t_{2}}=\left[a+(b-a) \pi_{i}^{t_{1}}\right]$. Note that despite these transformations, the numerical optimization procedure is free to search for any value of $\pi_{i}^{s_{i}}$ between $-\infty$ to $+\infty$. Once the maximum of the log likelihood function is obtained, we undo these transformations to solve for the elements of $\boldsymbol{\pi}^{s}$ which then lie between the ranges specified. It is important to note here that none of our constraints bind, i.e. in Table 2 neither our estimates nor the end points of their confidence intervals lie on any constraint boundaries. To obtain the standard errors, we undertake a parametric bootstrap (see, e.g. Efron and Tibshirani 1993) with 1000 replications. Finally note that our estimates imply a stable restricted $V A R(1)$ since the absolute maximum eigenvalue of the system matrix $\mathbf{T}$ is 0.98 . 
Table 2: Parameter estimates

\begin{tabular}{lcc}
\hline \hline & estimate & se \\
\hline$\alpha$ & 0.695 & 0.044 \\
$\beta$ & 0.959 & 0.013 \\
$\gamma$ & 0.488 & 0.159 \\
$\delta$ & 0.420 & 0.117 \\
$\zeta$ & 3.841 & 0.189 \\
$R$ & 0.347 & 0.140 \\
$\rho_{a}$ & 0.891 & 0.343 \\
$\rho_{q}$ & 0.863 & 0.094 \\
$A$ & 5.978 & 0.015 \\
$q$ & 0.502 & 0.162 \\
$\nu_{11}$ & 0.943 & 0.454 \\
$\nu_{12}$ & 0.724 & 0.295 \\
$\nu_{21}$ & 0.006 & 0.002 \\
$\nu_{22}$ & 0.895 & 0.488 \\
$\sigma_{a}$ & 0.002 & 0.001 \\
$\sigma_{q}$ & 0.425 & 0.020 \\
$\sigma_{\hat{y}^{\star}}$ & 0.044 & 0.012 \\
$\sigma_{\hat{q}^{\star}}$ & 0.014 & 0.004 \\
$\sigma_{\hat{y}^{\star} \hat{q}^{\star}}$ & 0.001 & 0.000 \\
\hline
\end{tabular}

The results reported in Table 2 above show that all of the structural parameters are significant and of reasonable magnitude. The estimated value of $\alpha$ implies a productivity of public capital, $(1-\alpha)$, of around 0.31 , which is similar to that in Aschauser (1989). The value of $\gamma$, the feedback policy coefficient in (14) measuring the effect of the endogenous state of the economy on the re-election probability, is positive as it should be and relatively high indicating that voters do look at the economy when they form their party preferences. The value of the weight given to public consumption relative to private consumption in the citizen's utility function, $\delta$, is similar to that found in Kormendi (1983) and Aschauer (1985) who report values between 0.2 to 0.4. The value of the weight given to leisure relative to private consumption in utility, $\zeta$, is almost four times the weight given to private consumption, which is similar to several $R B C$ calibrated values (see e.g. Chari et al., $1994,1995)$. The value of the extra rent when in power, $R$, is also found to be significant and positive confirming the assumption usually made in the $P B C$ literature. The estimated long-run probability of an incumbent being reelected, $q$, is 0.5 suggesting the absence of incumbency advantage in the 
steady-state. The persistence of technology and popularity shocks is high ${ }^{25}$, where the former is very close to those found in most $R B C$ models (see e.g. Cooley and Hansen, 1995).

\subsubsection{Model Diagnostics}

S-Tests Root mean square errors and bias-corrected $S$ tests of relative forecasting accuracy for 1-4 quarters ahead are reported in Table 3 below $^{26}$. To calculate these tests we estimate the model from 1947:1 to 1980:4 and use the remaining part of the full sample i.e. 1981:1 to 2004:2 to conduct the outof-sample forecasts ${ }^{27}$. Strictly speaking, the forecasts of our $D S G E$ model and those of the $U V A R$ are not comparable since our state-space model provides a forecast which includes an estimate of the measurement error. Accordingly, our forecasts will be of the "true" values of $\hat{y}$ and $\hat{q}$ whereas the $U V A R$ forecasts are based on the measured data only. Nonetheless this is a rough and ready method to assess the fit of our model relative to a non-structural benchmark model (see also Ireland (op cit.))

Table 3: Bias corrected S-tests

\begin{tabular}{lcccccccc}
\hline \hline Qtrs. & \multicolumn{2}{c}{ RMSE (Model) } & \multicolumn{2}{c}{ RMSE (UVAR) } & \multicolumn{2}{c}{ corrected S-test } & \multicolumn{2}{c}{ p-value } \\
Ahead & $\widehat{y}$ & $\widehat{q}$ & $\widehat{y}$ & $\widehat{q}$ & $\widehat{y}$ & $\widehat{q}$ & $\widehat{y}$ & $\widehat{q}$ \\
\hline 1 & 0.0583 & 0.1718 & 0.0655 & 0.1580 & 0.8679 & -1.6930 & 0.1927 & 0.0452 \\
2 & 0.0699 & 0.2052 & 0.0698 & 0.1870 & -0.0434 & -1.6058 & 0.4827 & 0.0542 \\
3 & 0.0839 & 0.2277 & 0.0798 & 0.2037 & -0.6871 & -1.4035 & 0.2460 & 0.0802 \\
4 & 0.0942 & 0.2471 & 0.0882 & 0.2140 & -0.6269 & -1.5814 & 0.2654 & 0.0569 \\
\hline
\end{tabular}

Overall, the results in Table 3 indicate (at the $5 \%$ level) that there is effectively no difference in the forecasting performance between the two models. The one exception here is that the $U V A R$ outperforms our DSGE model in the one quarter ahead frequency for $\hat{q}$. This is not surprising given that our process for $\hat{q}$ only depends on $\hat{y}$ indirectly in contrast to the direct link in the $U V A R$. It is also encouraging that despite the restrictions placed by the theory on the reduced form solution for $\hat{y}$, our model is not outperformed by the $U V A R$. This finding for $\hat{y}$ echoes the results in Ireland (op cit.).

Parameter stability Table 4 contains the results of parameter stability tests. These are obtained by re-estimating our model over two sub-periods

\footnotetext{
${ }^{25}$ For example the half life, $t^{*}=\ln (0.5) / \ln \left(\rho_{i}\right)$ of the shocks is 6.01 and 4.70 quarters respectively for the technology and electoral shocks.

${ }^{26}$ Note that the benchmark $U V A R(1)$ is based on $\widehat{y}_{t}$ and $\widehat{q}_{t}$, where both are detrended in the same manner as our DSGE model.

${ }^{27}$ The choice of these sub-samples is motivated below.
} 
and comparing the $90 \%$ confidence intervals for these estimates with each other and with those from the full sample. Our first estimation period runs from 1947:1 to 1980:4 and the second from 1981:1 to 2004:2. These subperiods are motivated in Ireland (op cit.) who argues, "The 1980 breakpoint corresponds, of course, to a date around which major changes in US monetary and fiscal policies are widely thought to have occurred".

The results in Table 4 show that all of our structural parameter estimates (which include the error variance for $q$ and $A$ ) contain confidence intervals which overlap. In other words, these estimates appear quite stable across the various samples employed. Turning to the parameters in the $V A R(1)$ for the measurement errors (which includes the $V A R$ error variances and covariance), we can see again that all confidence intervals overlap. However, note that for the three "starred" results the confidence intervals cover zero. In other words, the parameter $\nu_{21}$ is not significantly different from zero for the two sub-samples and the covariance between the measurement errors, $\sigma_{\hat{y}^{\star} \hat{q}^{\star}}$, is also not significant for the second sub-period.

Table 4: Parameter stability tests (90\% confidence intervals)

\begin{tabular}{lccc}
\hline \hline & Full Sample & Pre 1980 & Post 1980 \\
\hline$\alpha$ & {$[0.640 ; 0.750]$} & {$[0.668 ; 0.701]$} & {$[0.687 ; 0.721]$} \\
$\beta$ & {$[0.954 ; 0.990]$} & {$[0.956 ; 0.962]$} & {$[0.957 ; 0.973]$} \\
$\gamma$ & {$[0.049 ; 0.499]$} & {$[0.272 ; 0.323]$} & {$[0.293 ; 0.498]$} \\
$\delta$ & {$[0.340 ; 0.500]$} & {$[0.341 ; 0.429]$} & {$[0.327 ; 0.405]$} \\
$\zeta$ & {$[3.769 ; 4.000]$} & {$[3.721 ; 3.853]$} & {$[3.581 ; 3.841]$} \\
$R$ & {$[0.161 ; 0.500]$} & {$[0.136 ; 0.370]$} & {$[0.256 ; 0.385]$} \\
$A$ & {$[5.959 ; 5.987]$} & {$[5.977 ; 5.988]$} & {$[5.979 ; 5.980]$} \\
$q$ & {$[0.501 ; 0.915]$} & {$[0.501 ; 0.720]$} & {$[0.500 ; 0.813]$} \\
$\rho_{a}$ & {$[0.032 ; 0.990]$} & {$[0.084 ; 0.898]$} & {$[0.170 ; 0.888]$} \\
$\rho_{q}$ & {$[0.630 ; 0.889]$} & {$[0.671 ; 0.889]$} & {$[0.660 ; 0.879]$} \\
$\nu_{11}$ & {$[0.373 ; 1.540]$} & {$[0.376 ; 1.004]$} & {$[0.394 ; 1.186]$} \\
$\nu_{12}$ & {$[0.366 ; 1.111]$} & {$[0.355 ; 0.818]$} & {$[0.251 ; 0.762]$} \\
$\nu_{21}$ & {$[0.003 ; 0.009]$} & $*[-0.106 ; 0.152]$ & $*[-0.001 ; 0.118]$ \\
$\nu_{22}$ & {$[0.254 ; 1.549]$} & {$[0.675 ; 0.927]$} & {$[0.726 ; 0.981]$} \\
$\sigma_{a}$ & {$[0.001 ; 0.003]$} & {$[0.001 ; 0.004]$} & {$[0.001 ; 0.166]$} \\
$\sigma_{q}$ & {$[0.395 ; 0.446]$} & {$[0.376 ; 0.911]$} & {$[0.240 ; 0.653]$} \\
$\sigma_{\hat{y}^{\star}}$ & {$[0.012 ; 0.045]$} & {$[0.014 ; 0.070]$} & {$[0.011 ; 0.167]$} \\
$\sigma_{\hat{q}^{\star}}$ & {$[0.009 ; 0.020]$} & {$[0.051 ; 0.072]$} & {$[0.001 ; 0.219]$} \\
$\sigma_{\hat{y}^{\star} \hat{q}^{\star}}$ & {$[0.000 ; 0.001]$} & {$[0.000 ; 0.004]$} & $*[-0.012 ; 0.010]$ \\
\hline
\end{tabular}




\subsubsection{Innovation accounting}

Impulse responses To quantify the impacts that changes in electoral uncertainty have on the fiscal policy instruments and the macro-economy, as well as the impacts of changes in technology, we next present impulse responses to a temporary one-standard deviation shock to the innovations in electoral uncertainty and technology. Figure 1 reports the response of all endogenous variables to these transitory shocks (all in terms of deviations from their long-run value). For ease of comparison across the two sources of the shocks, the left- and right-hand side axes for each endogenous variable show the response to $\widehat{A}$ and $\widehat{q}$ shocks respectively. For example, the graph in the first row and first column of the Figure shows the effect on $\widehat{A}$ of an own shock (solid line) and the effect on $\widehat{A}$ of a shock to $\widehat{q}$ (dotted line). The latter is obviously zero since, as in common in the RBC literature, $\widehat{A}$ is generated by a simple $A R(1)$ process (see equation $6^{\prime \prime}$ ) and is thus not state dependent.

Row 2 of Figure 1 shows that the unit standard deviation shocks produce changes in private consumption and investment of similar magnitudes, with the slightly stronger effect resulting from the $\widehat{A}$-shock. Also note that most of the effects resulting from these shocks have dissipated after 5 years. The beneficial effects of the $\widehat{A}$-shock on private consumption and investment are as expected from standard RBC theory. In contrast, the private spending enhancing effects of the $\widehat{q}$-shock can be explained by referring to how policy endogenously responds to the shock. For example, the third row of the Figure (dotted lines) shows that in increase in the re-election probability leads to lower tax rates, $\widehat{\tau}_{t}$, and a higher share of tax revenues allocated to public investment relative to public consumption, $\widehat{\theta}_{t}$. In other words, a higher probability of re-election favors long-sighted policies. After the initial impact, the paths of both instruments exponentially return to their steadystates after about 5 years.

Given the state dependence of $\widehat{q}$, the solid lines in row 3 of Figure 1 show that the positive shock to $\widehat{A}$ is also conducive to policies which encourage capital accumulation. However, due to the endogeneity and persistence of $\widehat{q}$, it takes relatively longer (e.g. half-life is approximately 9 years) for the policy instruments to return to their steady-states ${ }^{28}$.

Row 4 of Figure 1 shows the effects on government investment and consumption deviations resulting from the two shocks. For example, in response to the $\widehat{A}$-shock both government consumption and investment increase by the same initial magnitude and both return to the steady-state after about 5 years (with government consumption returning slightly faster). In contrast,

\footnotetext{
${ }^{28}$ In contrast if $q$ were not state dependent, i.e. $\gamma=0, \widehat{\tau}_{t}$ and $\widehat{\theta}_{t}$ would be zero for all $t$ (see, e.g. equations $\left(17^{\prime}\right)$ and $\left.\left(18^{\prime}\right)\right)$.
} 
Figure 1: Impulse responses to $\widehat{A}$ and $\widehat{q}$ shocks
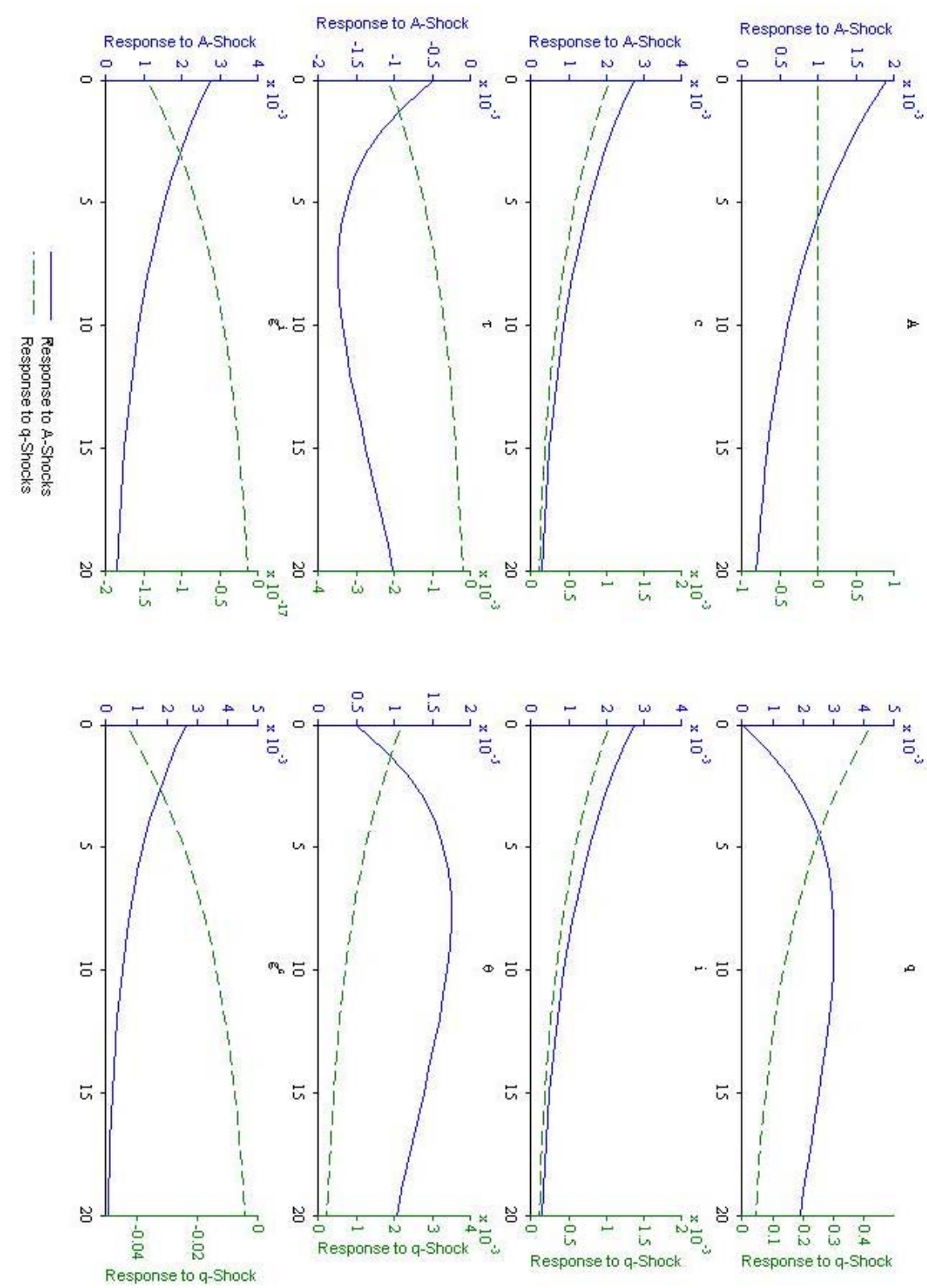
given the units on the right-hand scale of the $g^{i}$ graph, we can see that government investment effectively does not change in response to the $\widehat{q}$-shock whereas government consumption initially falls before exponentially returning to the steady-state after approximately 20 quarters. Despite no change in government investment, the following compositional changes in government spending are implied by this shock: $\frac{G^{c}}{G}$ and $\frac{G^{i}}{G}$ decrease and increase respectively and $\frac{G^{c}}{Y}, \frac{G^{i}}{Y}$ and $\frac{G}{Y}$ all decrease. In other words, after the positive shock to $\widehat{q}$, income taxes are lower and government spending is allocated more productively. Finally note that shocks to $\widehat{q}$ have no effect on $\widehat{y}$ for all $t$ since the positive effects on $\widehat{c}$ and $\widehat{i}$ are fully crowded out by the fall in $\widehat{g}^{c}$.

What about the implications for economic growth? From the definitions of output and investment deviations, it follows that equilibrium output growth is $\ln i$ (i.e. $1.71 \%$ ) and the transitional dynamics of output growth are dictated by $\ln Y_{t}-\ln Y_{t-1}=\widehat{i}_{t-1}+\ln i$. Using this information, in Table 5 we construct the response of economic growth resulting from the $\widehat{A}$ and $\widehat{q}$-shocks.

Table 5: Output Growth Impact

\begin{tabular}{ccccc}
\hline \hline & \multicolumn{2}{c}{$\hat{A}$} & \multicolumn{2}{c}{$\hat{q}$} \\
lag & estimate & se & estimate & se \\
\hline 0 & 1.983 & 0.3796 & 1.813 & 0.3734 \\
5 & 1.864 & 0.3845 & 1.768 & 0.3661 \\
10 & 1.797 & 0.3817 & 1.743 & 0.3640 \\
25 & 1.725 & 0.3759 & 1.716 & 0.3631 \\
50 & 1.711 & 0.3702 & 1.710 & 0.3630 \\
long-run & 1.710 & 0.3653 & 1.710 & 0.3630 \\
\hline
\end{tabular}

In Table 5 technology and popularity shocks have similar growth effects and are both significant, although the economic effect of technology shocks are larger and take slightly longer to dissipate. For example, the impact shock to $\widehat{A}$ and $\widehat{q}$ add about 0.3 and 0.1 points to the output growth respectively. Moreover the latter takes approximately 10 years to return to the steadystate for the $\hat{q}$ shock and $10+$ years for the $\widehat{A}$ shock.

Forecast error decompositions We first examine the relative contribution of technology versus political shocks in explaining the $k$-step-ahead forecast error variances in the components of output and the policy instruments (see Tables 6 and 7 ). Since private and public spending plus the policy instruments are part of the transition equations system, we cannot examine the relative contribution of the measurement errors. However, using the measurement equation system in Table 8 we also inspect the relative contribution of $\widehat{A}, \widehat{q}$ plus the two measurement errors in explaining the $k$-step-ahead forecast 
error variances in political uncertainty ${ }^{29}$. Note that, to save space, standard errors are not presented in Table 6-8. However further note that all of the results are statistically significant at least at the $5 \%$ level.

The results in Table 6 show that as expected, technology shocks have the greatest explanatory power for the private spending components plus government investment. The latter follows since as shown above, while $G^{i} / G$ increases, government investment does not change in response to increases in $\widehat{q}$. Nonetheless changes in political uncertainty significantly explain nearly $13 \%$ of the error variance in $\widehat{c}$ and $\widehat{i}$ and nearly all of the error variance in government consumption. Likewise, as expected given our model specification, Table 7 shows that political uncertainty significantly explains nearly all of the error variance in the two policy instruments. As mentioned above, we cannot assess the relative contribution of measurement errors at this stage since we are using the transition equation system for Tables 6-7.

Table 6: Private \& public spending

\begin{tabular}{|c|c|c|c|c|c|c|c|c|}
\hline Qtrs. & \multicolumn{2}{|c|}{$\widehat{c}$} & \multicolumn{2}{|c|}{$i$} & \multicolumn{2}{|c|}{$\widehat{g}^{i}$} & \multicolumn{2}{|c|}{$\widehat{g}^{c}$} \\
\hline Ahead & $A$ & $\widehat{q}$ & $A$ & $\widehat{q}$ & $\bar{A}$ & $\widehat{q}$ & $\bar{A}$ & $\widehat{q}$ \\
\hline 1 & 0.8745 & 0.1255 & 0.8745 & 0.1255 & 1.0000 & 0.0000 & 0.0034 & 0.9966 \\
\hline 4 & 0.8746 & 0.1254 & 0.8746 & 0.1254 & 1.0000 & 0.0000 & 0.0031 & 0.9969 \\
\hline 8 & 0.8746 & 0.1254 & 0.8746 & 0.1254 & 1.0000 & 0.0000 & 0.0028 & 0.9972 \\
\hline 12 & 0.8747 & 0.1253 & 0.8747 & 0.1253 & 1.0000 & 0.0000 & 0.0027 & 0.9973 \\
\hline 20 & 0.8747 & 0.1253 & 0.8747 & 0.1253 & 1.0000 & 0.0000 & 0.0026 & 0.9974 \\
\hline 40 & 0.8747 & 0.1253 & 0.8747 & 0.1253 & 1.0000 & 0.0000 & 0.0025 & 0.9975 \\
\hline$\infty$ & 0.8747 & 0.1253 & 0.8747 & 0.1253 & 1.0000 & 0.0000 & 0.0025 & 0.9975 \\
\hline
\end{tabular}

\footnotetext{
${ }^{29}$ We exclude the decomposition of the output error variance given the full crowding out of $\widehat{y}$ by shocks to $\widehat{q}$. This property implies that the contribution of shocks to $\widehat{q}$ in explaining the forecast error variance in $\widehat{y}$ will be zero. Not surprisingly, given other finding in the RBC literature, shocks to $\widehat{A}$ explain about $60 \%$ of the forecast error variance in $\widehat{y}$ initially. However, in contrast to standard RBC models, this share eventually falls instead of increases. This difference is most probably explained by our simple private sector setup which was adopted here so that we could focus on a richer description of policy.
} 
Table 7: Policy instruments

\begin{tabular}{lcccc}
\hline Qtrs. & \multicolumn{2}{c}{$\widehat{\tau}$} & \multicolumn{2}{c}{$\widehat{\theta}$} \\
Ahead & $\widehat{A}$ & $\widehat{q}$ & $\widehat{A}$ & $\widehat{q}$ \\
\hline 1 & 0.0000 & 1.0000 & 0.0000 & 1.0000 \\
4 & 0.0001 & 0.9999 & 0.0001 & 0.9999 \\
8 & 0.0001 & 0.9999 & 0.0001 & 0.9999 \\
12 & 0.0002 & 0.9998 & 0.0002 & 0.9998 \\
20 & 0.0002 & 0.9998 & 0.0002 & 0.9998 \\
40 & 0.0003 & 0.9997 & 0.0003 & 0.9997 \\
$\infty$ & 0.0003 & 0.9997 & 0.0003 & 0.9997 \\
\hline
\end{tabular}

Consistent with the focus of the paper, we can assess the relative contribution of all four innovations (i.e. two structural and two measurement) in explaining the observed variation in political uncertainty. Table 8 suggests that in the short-run, innovations to $\widehat{q}$ plus the measurement errors in political uncertainty, $\nu_{2 t}$, explain most of the forecast error variance in $\widehat{q}$. However, in the long-run nearly $75 \%$ of the latter is explained by technology innovations. This suggests that economic growth matters for political stability.

Table 8: Electoral Uncertainty

\begin{tabular}{lcccc}
\hline \hline Qtrs. & \multicolumn{4}{c}{$\widehat{q}$} \\
Ahead & $\widehat{A}$ & $\widehat{q}$ & $\nu_{1 t}$ & $\nu_{2 t}$ \\
\hline 1 & 0.0518 & 0.4732 & 0.0000 & 0.4750 \\
4 & 0.3423 & 0.3241 & 0.0001 & 0.3335 \\
8 & 0.5878 & 0.1979 & 0.0001 & 0.2141 \\
12 & 0.6917 & 0.1437 & 0.0002 & 0.1644 \\
20 & 0.7587 & 0.1064 & 0.0003 & 0.1346 \\
40 & 0.7688 & 0.0928 & 0.0006 & 0.1378 \\
$\infty$ & 0.7450 & 0.0895 & 0.0011 & 0.1644 \\
\hline
\end{tabular}

\section{Conclusions}

This paper has solved a tractable benchmark DSGE model to study the link between elections, fiscal policy and fluctuations/growth. The model was then formally estimated for the US by using Ireland's (2004) flexible hybrid estimation methodology. The focus has been on the effects of electoral uncertainty upon the choice of fiscal policy instruments and in turn upon the macro-economy.

The main theoretical result is that electoral uncertainty pushes governments to follow relatively short-sighted fiscal policies and this is detrimental 
for the macro-economy. There are two aspects to our transmission mechanism worth pointing out. First, it is the assumption that the parties' instantaneous payoff is higher when in power than when out of power, in combination with electoral (probabilistic) uncertainty, that leads to short-sighted policies and electoral business cycles in general. With rational forward-looking policymakers, if we relax any of these two assumptions, the problem collapses to a single government case. Second, the assumption that the re-election probability is endogenous depending on the current performance of the economy reduces but cannot eliminate these electoral effects. Again, what is crucial is that the incumbent knows that he/she may be replaced in the coming election by another politician and that there is an extra rent when in power ${ }^{30}$.

Our econometric results have provided clear support for these propositions. By explicitly modeling the behavioral channel through which the election process affects the macroeconomy, we found statistically significant effects of electoral shocks on the policy instruments and the various components of output. In particular, there is evidence that shocks to electoral uncertainty lead to higher tax rates and less productive use of government spending. Qualitatively, positive popularity and technology shocks have similar beneficial effects on private spending (consumption and investment) and economic growth. Quantitatively, the effects on the policy instruments are dominated by electoral shocks, while private spending and economic growth (as expected) are affected more by technology than by electoral shocks. Finally our forecast error decompositions revealed that while political shocks dominate productivity shocks in the short-run, in the long-run, economic growth is what matters most for political stability.

Our research contributes to both the literature on political business cycles, as well as the quantitative $R B C$ literature. It adds to the former mainly because, to the extent that we formally estimated the solution of the theoretical model, we filled a gap between theoretical and empirical research. To date, there has been very little econometric work, which has successfully made the formal link between electoral uncertainty, endogenous fiscal policy and ultimately aggregate outcomes. Our research also adds to the $R B C$ literature because we departed from the world of a centralized economy and a benevolent single government. This allowed us to incorporate some important policy choices. We also obtained estimated values of a number of stable parameters which are of key interest in a variety of $D S G E$ modeling contexts.

\footnotetext{
${ }^{30}$ See e.g. Lockwood et al. (1996) and Economides et al. (2003) for more details on these points.
} 


\section{References}

[1] Alesina A., N. Roubini and G. Cohen (1997): Political Cycles and the Macroeconomy. MIT Press, Cambridge, Mass.

[2] Alesina A. and J. Sachs (1988): Political parties and business cycle in the US 1948-84, Journal of Money, Credit and Banking, 20, 63-82.

[3] Alesina A. and G. Tabellini (1990): A positive theory of fiscal deficits and government debt, Review of Economic Studies, 57, 403-414.

[4] Andrews, D.W.K. and R.C. Fair (1988): Inference in Nonlinear Econometric Models with Structural Change, Review of Economic Studies, 55: 615-39.

[5] Aschauer, D. (1989): Is public expenditure productive?, Journal of Monetary Economics, 23, 177-200.

[6] Baier S. and G. Glomm (2001): Long-run growth and welfare effects of public policies with distortionary taxation, Journal of Economic Dynamic and Control, 25, 2007-2042.

[7] Barro R. and X. Sala-i-Martin (2004): Economic Growth. McGraw Hill (2nd ed).

[8] Barro R. (1990): Government spending in a simple model of endogenous growth, Journal of Political Economy, 98, S103-S125.

[9] Barro, R. (1989): The neoclassical approach to fiscal policy, in Modern Business Cycle Theory, edited by R. Barro, Blackwell.

[10] Baxter M. and R. King (1993): Fiscal policy in general equilibrium, American Economic Review, 83, 315-334.

[11] Campbell J. (1993): Intertemporal asset pricing without consumption data, American Economic Review, 83, 487-511.

[12] Campbell J. and L. Viceira (2002): Strategic Asset Allocation. Oxford University Press, Oxford.

[13] Chari V., L. Christiano and P. Kehoe (1995): Policy analysis in business cycle models, in Frontiers of Business Cycle Research, edited by T. Cooley. Princeton University Press.

[14] Chari V. L. Christiano and P. Kehoe (1994): Optimal fiscal policy in a business cycle model, Journal of Political Economy, 102, 617-652. 
[15] Christiano L. and M. Eichenbaum (1992): Current and real-businesscycle theories and aggregate labor-market fluctuations, American Economic Review, 82, 430-450.

[16] Cooley T. and G. Hansen (1995): Money and the business cycle, in Frontiers of Business Cycle Research, edited by T. Cooley. Princeton University Press.

[17] Devarajan S., V. Swaroop and H. Zou (1996): The composition of public expenditure and economic growth, Journal of Monetary Economics, 37, 313-344.

[18] Devereux M. and J-F. Wen (1998): Political instability, capital taxation and growth, European Economic Review, 42, 1635-1651.

[19] Diebold, Francis X. and Roberto S. Mariano (1995): Comparing predictive accuracy, Journal of Business and Economic Statistics, 13: 253-63.

[20] Dixit A., G. Grossman and F. Gul (2000): The dynamics of political compromise, Journal of Political Economy, 108, 531-568.

[21] Drazen A. (2000): Political Economy in Macroeconomics. Princeton University Press, Princeton.

[22] Economides G., A. Philippopoulos and S. Price (2003): How elections affect fiscal policy and growth: revisiting the mechanism, European Journal of Political Economy, 19, 777-792.

[23] Efron, B. and R. Tibshirani (1993): An Introduction to the Bootstrap, Chapman and Hall/CRC.

[24] Eisenberg, D. and J. Ketcham (2004): Economic voting in U.S. presidential elections: Who blames whom for what, Topics in Economic Analysis \& Policy: Vol. 4: No. 1, Article 19; http://www.bepress.com/bejeap/topics/vol4/iss1/art19.

[25] Gali J. (1994): Government size and macroeconomic stability, European Economic Review, 38, 117-132.

[26] Harvey, D., S. Leybourne, and P. Newbold (1997): Testing the equality of prediction mean squared errors, International Journal of Forecasting, 13: 281-91.

[27] Harvey A.C. (1989): Forecasting, Structural Time Series Models and the Kalman Filter, Cambridge University Press. 
[28] Ireland, P.N. (2004): A method for taking models to the data, Journal of Economic Dynamics and Control, 24: 1205-26.

[29] King R. and S. Rebelo (1999): Resuscitating real business cycles, in Handbook of Macroeconomics, volume 1B, edited by J. Taylor and M. Woodford, North-Holland.

[30] Klein P., and J.-V. Rios-Rull (2003): Time-consistent optimal fiscal policy, International Economic Review, 44, 1217-1245.

[31] Kneller R., M. Bleaney and N. Gemmell (1999): Fiscal policy and growth: evidence from OECD countries, Journal of Public Economics, 74, 171-190.

[32] Kormendi, R. (1983): Government debt, government spending, and private sector behavior, American Economic Review, 73, 994-1010.

[33] Lansing K. (1998): Optimal fiscal policy in a business cycle model with public capital, Canadian Journal of Economics, 31, 337-364.

[34] Ljungqvist L. and T. Sargent (2000): Recursive Macroeconomic Theory. The MIT Press, Cambridge, Mass.

[35] Lockwood B., A. Philippopoulos and A. Snell (1996): Fiscal policy, public debt stabilization and politics: theory and UK evidence, Economic Journal, 106, 894-911.

[36] Lucas R. E., Jr. (1990): Supply side economics: an analytical review, Oxford Economic Papers, 42, 293-316.

[37] McCallum B. (1989): Real business cycle models, in Modern Business Cycle Theory, edited by R. Barro. Blackwell, London.

[38] McGrattan E. (1994): The macroeconomic effects of distortionary taxation, Journal of Monetary Economics, 33, 573-601.

[39] Park H. and A. Philippopoulos (2003): On the dynamics of growth and fiscal policy with redistributive transfers, Journal of Public Economics, $87,515-538$.

[40] Park H. and A. Philippopoulos (2004): Indeterminacy and fiscal policies in a growing economy, Journal of Economic Dynamics and Control, 28, 645-660. 
[41] Persson T. and G. Tabellini (1999): Political economics and macroeconomic policy, in Handbook of Macroeconomics, vol. 1C, edited by J. Taylor and M. Woodford. North-Holland, Amsterdam.

[42] Persson T. and G. Tabellini (2000): Political Economics: Explaining Economic Policy. MIT Press. Cambridge, Mass.

[43] Price S. and D. Sanders (1994): Economic competence, rational expectations and government popularity in post-war Britain, Manchester School, 62, 296-312.

[44] Sargent T. (1987): Dynamic Macroeconomic Theory. Harvard University Press, Cambridge, Mass.

[45] Sargent, T. (1989): Two models of measurements and the investment accelerator", Journal of Political Economy, 97: 251-87.

[46] Tanzi V. and Schuknecht L. (2000): Public spending in the 20th century. Cambridge University Press, Cambridge. 


\section{Appendices}

\subsection{Appendix A: Result 1}

The first-order conditions of the household's dynamic problem are

$$
\begin{gathered}
\frac{1}{C_{t}}=\beta E_{t}\left[\frac{\left(1-\tau_{t+1}\right) r_{t+1}}{C_{t+1}}\right] \\
\frac{\zeta}{1-L_{t}}=\frac{\left(1-\tau_{t}\right) w_{t}}{C_{t}}
\end{gathered}
$$

and the budget constraint in (3).

The first-order conditions of the firm's static problem are

$$
r_{t}=\frac{\alpha Y_{t}}{K_{t}}
$$

and

$$
w_{t}=\frac{(1-\alpha) Y_{t}}{L_{t}} .
$$

In a $C D E$ by using (8) and $Y_{t}=r_{t} K_{t}+w_{t} L_{t}+\pi_{t}$ with $\pi_{t}=0$, output is given by

$$
Y_{t}=A_{t}^{1 / \alpha} K_{t}\left(\tau_{t} \theta_{t} L_{t}\right)^{(1-\alpha) / \alpha} .
$$

Moreover, we conjecture that $L_{t}$ does not change over time and that $C_{t}$ and $K_{t+1}$ are proportional to the product

$$
A_{t}^{1 / \alpha}\left(1-\tau_{t}\right) K_{t}\left(\tau_{t} \theta_{t} L_{t}\right)^{(1-\alpha) / \alpha}
$$

where the assumed degrees of proportionality are time-invariant (for further details, see McCallum 1989, pp. 21-22). Then substituting these conjectures into (A1) we obtain $K_{t+1}$. In turn by using (3) we get $C_{t}$ and by using (A2) we find $L_{t}$. These three solutions are given in Result 1 . The solutions for $G_{t}^{i}$ and $G_{t}^{c}$ follow respectively from (8) and (9).

\subsection{Appendix B: Result 2}

If we differentiate the right-hand side of (15) with respect to $\tau_{t}^{h}$ and $\theta_{t}^{h}$, and impose the ex post symmetry conditions $\tau_{t}^{h}=\tau_{t}^{j} \equiv \tau_{t}, \theta_{t}^{h}=\theta_{t}^{j} \equiv \theta_{t}$, $u^{P_{h}}=u^{P_{j}} \equiv u^{P}$ and $u^{N_{h}}=u^{N_{j}} \equiv u^{N}$; then the first-order conditions for $\tau_{t}$ and $\theta_{t}$ become:

$$
\begin{aligned}
0= & \frac{\delta}{\alpha \tau_{t}}-\frac{\left(\tau_{t}+\alpha-1\right)}{\alpha \tau_{t}\left(1-\tau_{t}\right)}+\beta E_{t}\left[q_{t+1} \frac{\partial V^{P}(t+1)}{\partial \tau_{t}}+\right. \\
& \left.+\left(1-q_{t+1}\right) \frac{\partial V^{N}(t+1)}{\partial \tau_{t}}+\left\{V^{P}(t+1)-V^{N}(t+1)\right\} \frac{\partial q_{t+1}}{\partial \tau_{t}}\right]
\end{aligned}
$$




$$
\begin{aligned}
0= & \frac{(1-\alpha)}{\alpha \theta_{t}}-\frac{\delta\left(\theta_{t}+\alpha-1\right)}{\alpha \theta_{t}\left(1-\theta_{t}\right)}+\beta E_{t}\left[q_{t+1} \frac{\partial V^{P}(t+1)}{\partial \theta_{t}}+\right. \\
& \left.+\left(1-q_{t+1}\right) \frac{\partial V^{N}(t+1)}{\partial \theta_{t}}+\left\{V^{P}(t+1)-V^{N}(t+1)\right\} \frac{\partial q_{t+1}}{\partial \theta_{t}}\right]
\end{aligned}
$$

First consider the term $\left\{V^{P}(t+1)-V^{N}(t+1)\right\}$ on the right-hand side of (B1-B2). In a symmetric equilibrium, the policies chosen by party $j$ when in power (during which party $h$ is out of power) are the same as those chosen by party $h$ when in power (during which party $j$ is out of power). Hence, for a given state of the economy, equations (10)-(13) imply that private and public consumption will also be the same when in and when out of power. Hence,

$$
\begin{aligned}
& \left\{V^{P}(t+1)-V^{N}(t+1)\right\} \\
= & \sum_{t=1}^{\infty} \beta^{t}\left(R+\ln C_{t}+\delta \ln G_{t}^{c}\right)-\sum_{t=1}^{\infty} \beta^{t}\left(\ln C_{t}+\delta \ln G_{t}^{c}\right) \\
= & \frac{\beta R}{(1-\beta)} .
\end{aligned}
$$

Consider next the partial derivatives on the right-hand side of (B.1)-(B.2). If we use the conjectures for the value functions, namely $V^{P_{h}}\left(K_{t} ; q_{t}, A_{t}\right)=$ $u_{0}^{P_{h}}+u_{1}^{P_{h}} \ln K_{t}+u_{2}^{P_{h}} \ln q_{t}+u_{3}^{P_{h}} \ln A_{t}$ and $V^{N_{h}}\left(K_{t} ; q_{t}, A_{t}\right)=u_{0}^{N_{h}}+u_{1}^{N_{h}} \ln K_{t}+$ $u_{2}^{N_{h}} \ln q_{t}+u_{3}^{N_{h}} \ln A_{t}$, where $u_{0}^{P_{h}}, u_{1}^{P_{h}}, u_{2}^{P_{h}}, u_{3}^{P_{h}}, u_{0}^{N_{h}}, u_{1}^{N_{h}}, u_{2}^{N_{h}}, u_{3}^{N_{h}} \geq 0$ are timeinvariant undetermined coefficients, we have the following partial derivatives in a symmetric equilibrium:

$$
\begin{array}{cl}
\frac{\partial V^{P}(t+1)}{\partial \tau_{t}}=\frac{\left(1-\alpha-\tau_{t}\right)}{\alpha \tau_{t}\left(1-\tau_{t}\right)}\left(u_{1}^{P}+\gamma u_{2}^{P}\right), & \frac{\partial V^{N}(t+1)}{\partial \tau_{t}}=\frac{\left(1-\alpha-\tau_{t}\right)}{\alpha \tau_{t}\left(1-\tau_{t}\right)}\left(u_{1}^{N}+\gamma u_{2}^{N}\right), \\
\frac{\partial V^{P}(t+1)}{\partial \theta_{t}}=\frac{(1-\alpha)}{\alpha \theta_{t}}\left(u_{1}^{P}+\gamma u_{2}^{P}\right), & \frac{\partial V^{N}(t+1)}{\partial \theta_{t}}=\frac{(1-\alpha)}{\alpha \theta_{t}}\left(u_{1}^{N}+\gamma u_{2}^{N}\right) .
\end{array}
$$

Using (B.3)-(B.4) into (B.1)-(B.2), we obtain:

$$
\begin{aligned}
\frac{\delta\left(1-\tau_{t}\right)}{\left(\tau_{t}+\alpha-1\right)}= & {\left[1+\beta\left(u_{1}^{N}+\gamma u_{2}^{N}\right)\right.} \\
& \left.+\beta E_{t} q_{t+1}\left\{\left(u_{1}^{P}-u_{1}^{N}\right)+\gamma\left(u_{2}^{P}-u_{2}^{N}\right)\right\}+\frac{\beta^{2} \gamma R E_{t} q_{t+1}}{(1-\beta)}\right] \\
\frac{\delta\left(\theta_{t}+\alpha-1\right)}{(1-\alpha)\left(1-\theta_{t}\right)}= & {\left[1+\beta\left(u_{1}^{N}+\gamma u_{2}^{N}\right)\right.} \\
& \left.+\beta E_{t} q_{t+1}\left\{\left(u_{1}^{P}-u_{1}^{N}\right)+\gamma\left(u_{2}^{P}-u_{2}^{N}\right)\right\}+\frac{\beta^{2} \gamma R E_{t} q_{t+1}}{(1-\beta)}\right]
\end{aligned}
$$


Equations (B.5)-(B.6) are not reduced-form solutions for $\tau_{t}$ and $\theta_{t}$ because they include the undermined coefficients. Nevertheless, they can provide some useful information. For instance, since we expect (and this is confirmed below) $\left(u_{1}^{P}-u_{1}^{N}\right) \geq 0$ and $\left(u_{2}^{P}-u_{2}^{N}\right) \geq 0$ (i.e. the parties cannot be worse off when in power), they imply $\tau_{t}>(1-\alpha)$ and $\theta_{t}>(1-\alpha)$ along the optimal path. Also, it is worth pointing out that if the re-election probability, $q_{t+1}$, were exogenous (namely, not a function of $i_{t} / i$ or any other endogenous variable), it would be possible to obtain analytic results at this stage showing that when the re-election probability increases, rational policymakers find it optimal to choose a lower tax rate, $\tau_{t}$, and a higher share allocated to public investment vis-à-vis public consumption, $\theta_{t}{ }^{31}$. However, with endogenous re-election probabilities, it is not possible to show this without resorting to special cases. We therefore prefer not to present any policy properties at this stage, but instead use impulse response functions to quantify the reactions of the policy instruments, $\tau_{t}$ and $\theta_{t}$, to random shocks to $q_{t}$, and in turn the control variables in (10)-(13).

Next, we take a linear approximation of (B.5)-(B.6) around the model consistent long-run equilibrium. It is then straightforward to show that we obtain equations (17)-(18) in the main body of the paper where $\Omega_{1}-\Omega_{6}$ are also defined there and $M \equiv \beta\left\{\left(u_{1}^{P}-u_{1}^{N}\right)+\gamma\left(u_{2}^{P}-u_{2}^{N}\right)\right\}$.

It remains to solve for the undetermined coefficients. Actually, what we are interested in is the value of $M$ that affects the choice of the policy instruments. We work as follows. We go back to (15)-(16), use the conjectures for the value functions, and take a first-order approximation around the longrun. Then, we use (17)-(18) for $\widehat{\theta}_{t}$ and $\widehat{\tau}_{t}$, as well as (10), (11), (13), (14) and (6) to obtain $\widehat{C}_{t}, \widehat{K}_{t+1}, \widehat{G}_{t}^{c}, \widehat{q}_{t+1}$, and $\widehat{A}_{t+1}$, respectively ${ }^{32}$. We also make use of (B.3). Substituting all these equations back into (15)-(16), and equating coefficients on $\widehat{K}_{t}$ on both sides of (15)-(16), we obtain a system of two Riccati equations in $u_{1}^{P}$ and $u_{1}^{N}$, whose solution gives $u_{1}^{P}=u_{1}^{N}=\frac{1+\delta}{1-\beta}>0$. Working similarly, if we equate coefficients on $\widehat{q}_{t}$ on both sides of (15)-(16), we obtain a system of two Riccati equations in $u_{2}^{P}$ and $u_{2}^{N}$, which imply $\left(u_{2}^{P}-u_{2}^{N}\right)=\frac{\Omega_{7} 2 \beta^{2} R q}{(1-\beta)\left[1+\Omega_{7} \beta(1-2 q)\right]}$, where $\Omega_{7} \equiv \rho_{q}\left(1+\frac{\gamma(1-\alpha) \Omega_{5}}{\alpha}+\frac{\gamma(1-\alpha-\tau) \Omega_{6}}{\alpha(1-\tau)}\right)$. Thus, $M=\beta \gamma\left(\frac{\Omega_{7} 2 \beta^{2} R q}{(1-\beta)\left[1+\Omega_{7} \beta(1-2 q)\right]}\right)$ as in the main text. Note that our numerical simulations will quantify $\left(u_{2}^{P}-u_{2}^{N}\right)$, and hence $M$, which we expect

\footnotetext{
${ }^{31}$ These results are available upon request.

${ }^{32}$ Thus, $\widehat{C}_{t}=\frac{1}{\alpha} \widehat{A}_{t}+\frac{(1-\alpha-\tau)}{\alpha(1-\tau)} \widehat{\tau}_{t}+\frac{(1-\alpha)}{\alpha} \widehat{\theta}_{t}+\widehat{K}_{t}, \widehat{K}_{t+1}=\frac{1}{\alpha} \widehat{A}_{t}+\frac{(1-\alpha-\tau)}{\alpha(1-\tau)} \widehat{\tau}_{t}+\frac{(1-\alpha)}{\alpha} \widehat{\theta}_{t}+\widehat{K}_{t}$, and $\widehat{G}_{t}^{c}=\frac{1}{\alpha} \widehat{A}_{t}+\frac{1}{\alpha} \widehat{\tau}_{t}+\frac{(1-\alpha-\theta)}{\alpha(1-\theta)} \widehat{\theta}_{t}+\widehat{K}_{t}$. Also, given the information set, $\widehat{q}_{t+1}=\rho_{q} q_{t}+$ $\gamma\left[\frac{1}{\alpha} \widehat{A}_{t}+\frac{(1-\alpha-\tau)}{\alpha(1-\tau)} \widehat{\tau}_{t}+\frac{(1-\alpha)}{\alpha} \widehat{\theta}_{t}\right]+\varepsilon_{t+1}$ and $\widehat{A}_{t+1}=\rho_{a} A_{t}+\eta_{t+1}$.
} 
both to be positive.

\subsection{Appendix C: Policy instruments in the steady-state}

In the long-run, $\widehat{\theta}_{t}=\widehat{\tau}_{t}$ requires $\Omega_{5}=\Omega_{6}=0$ in (17)-(18), which in turn necessitates $R=M=0$. Thus, in the long-run, there cannot be any extra rents from being in power, $R=0$, and hence the valuation coefficients are the same when in and when out of power, i.e. $M \equiv \beta\left\{\left(u_{1}^{P}-u_{1}^{N}\right)+\gamma\left(u_{2}^{P}-u_{2}^{N}\right)\right\}=0$. Using these conditions into the Riccati equations for $u_{2}^{P}$ and $u_{2}^{N}$, we get $u_{2}^{P}=u_{2}^{N}=0$. Substituting all this into the first-order conditions (B.5)(B.6), we obtain the long-run solutions for $\tau$ and $\theta$ reported in the body of the paper (see Subsection 2.7). As stated earlier, this coincides with the solution of a benevolent single government i.e. $q_{t}=1$ and $R=0$ for all $t$ in (15)-(16). 


\title{
CESifo Working Paper Series
}

\author{
(for full list see www.cesifo-group.de)
}

1529 Giorgio Fazio, Ronald MacDonald and Jacques Mélitz, Trade Costs, Trade Balances and Current Accounts: An Application of Gravity to Multilateral Trade, August 2005

1530 Thomas Christiaans, Thomas Eichner and Ruediger Pethig, A Micro-Level 'Consumer Approach’ to Species Population Dynamics, August 2005

1531 Samuel Hanson, M. Hashem Pesaran and Til Schuermann, Firm Heterogeneity and Credit Risk Diversification, August 2005

1532 Mark Mink and Jakob de Haan, Has the Stability and Growth Pact Impeded Political Budget Cycles in the European Union?, September 2005

1533 Roberta Colavecchio, Declan Curran and Michael Funke, Drifting Together or Falling Apart? The Empirics of Regional Economic Growth in Post-Unification Germany, September 2005

1534 Kai A. Konrad and Stergios Skaperdas, Succession Rules and Leadership Rents, September 2005

1535 Robert Dur and Amihai Glazer, The Desire for Impact, September 2005

1536 Wolfgang Buchholz and Wolfgang Peters, Justifying the Lindahl Solution as an Outcome of Fair Cooperation, September 2005

1537 Pieter A. Gautier, Coen N. Teulings and Aico van Vuuren, On-the-Job Search and Sorting, September 2005

1538 Leif Danziger, Output Effects of Inflation with Fixed Price- and Quantity-Adjustment Costs, September 2005

1539 Gerhard Glomm, Juergen Jung, Changmin Lee and Chung Tran, Public Pensions and Capital Accumulation: The Case of Brazil, September 2005

1540 Yvonne Adema, Lex Meijdam and Harrie A. A. Verbon, The International Spillover Effects of Pension Reform, September 2005

1541 Richard Disney, Household Saving Rates and the Design of Social Security Programmes: Evidence from a Country Panel, September 2005

1542 David Dorn and Alfonso Sousa-Poza, Early Retirement: Free Choice or Forced Decision?, September 2005

1543 Clara Graziano and Annalisa Luporini, Ownership Concentration, Monitoring and Optimal Board Structure, September 2005 
1544 Panu Poutvaara, Social Security Incentives, Human Capital Investment and Mobility of Labor, September 2005

1545 Kjell Erik Lommerud, Frode Meland and Odd Rune Straume, Can Deunionization Lead to International Outsourcing?, September 2005

1546 Robert Inklaar, Richard Jong-A-Pin and Jakob de Haan, Trade and Business Cycle Synchronization in OECD Countries: A Re-examination, September 2005

1547 Randall K. Filer and Marjorie Honig, Endogenous Pensions and Retirement Behavior, September 2005

1548 M. Hashem Pesaran, Til Schuermann and Bjoern-Jakob Treutler, Global Business Cycles and Credit Risk, September 2005

1549 Ruediger Pethig, Nonlinear Production, Abatement, Pollution and Materials Balance Reconsidered, September 2005

1550 Antonis Adam and Thomas Moutos, Turkish Delight for Some, Cold Turkey for Others?: The Effects of the EU-Turkey Customs Union, September 2005

1551 Peter Birch Sørensen, Dual Income Taxation: Why and how?, September 2005

1552 Kurt R. Brekke, Robert Nuscheler and Odd Rune Straume, Gatekeeping in Health Care, September 2005

1553 Maarten Bosker, Steven Brakman, Harry Garretsen and Marc Schramm, Looking for Multiple Equilibria when Geography Matters: German City Growth and the WWII Shock, September 2005

1554 Paul W. J. de Bijl, Structural Separation and Access in Telecommunications Markets, September 2005

1555 Ueli Grob and Stefan C. Wolter, Demographic Change and Public Education Spending: A Conflict between Young and Old?, October 2005

1556 Alberto Alesina and Guido Tabellini, Why is Fiscal Policy often Procyclical?, October 2005

1557 Piotr Wdowinski, Financial Markets and Economic Growth in Poland: Simulations with an Econometric Model, October 2005

1558 Peter Egger, Mario Larch, Michael Pfaffermayr and Janette Walde, Small Sample Properties of Maximum Likelihood Versus Generalized Method of Moments Based Tests for Spatially Autocorrelated Errors, October 2005

1559 Marie-Laure Breuillé and Robert J. Gary-Bobo, Sharing Budgetary Austerity under Free Mobility and Asymmetric Information: An Optimal Regulation Approach to Fiscal Federalism, October 2005 
1560 Robert Dur and Amihai Glazer, Subsidizing Enjoyable Education, October 2005

1561 Carlo Altavilla and Paul De Grauwe, Non-Linearities in the Relation between the Exchange Rate and its Fundamentals, October 2005

1562 Josef Falkinger and Volker Grossmann, Distribution of Natural Resources, Entrepreneurship, and Economic Development: Growth Dynamics with Two Elites, October 2005

$1563 \mathrm{Yu}-\mathrm{Fu}$ Chen and Michael Funke, Product Market Competition, Investment and Employment-Abundant versus Job-Poor Growth: A Real Options Perspective, October 2005

1564 Kai A. Konrad and Dan Kovenock, Equilibrium and Efficiency in the Tug-of-War, October 2005

1565 Joerg Breitung and M. Hashem Pesaran, Unit Roots and Cointegration in Panels, October 2005

1566 Steven Brakman, Harry Garretsen and Marc Schramm, Putting New Economic Geography to the Test: Free-ness of Trade and Agglomeration in the EU Regions, October 2005

1567 Robert Haveman, Karen Holden, Barbara Wolfe and Andrei Romanov, Assessing the Maintenance of Savings Sufficiency Over the First Decade of Retirement, October 2005

1568 Hans Fehr and Christian Habermann, Risk Sharing and Efficiency Implications of Progressive Pension Arrangements, October 2005

1569 Jovan Žamac, Pension Design when Fertility Fluctuates: The Role of Capital Mobility and Education Financing, October 2005

1570 Piotr Wdowinski and Aneta Zglinska-Pietrzak, The Warsaw Stock Exchange Index WIG: Modelling and Forecasting, October 2005

1571 J. Ignacio Conde-Ruiz, Vincenzo Galasso and Paola Profeta, Early Retirement and Social Security: A Long Term Perspective, October 2005

1572 Johannes Binswanger, Risk Management of Pension Systems from the Perspective of Loss Aversion, October 2005

1573 Geir B. Asheim, Wolfgang Buchholz, John M. Hartwick, Tapan Mitra and Cees Withagen, Constant Savings Rates and Quasi-Arithmetic Population Growth under Exhaustible Resource Constraints, October 2005

1574 Christian Hagist, Norbert Klusen, Andreas Plate and Bernd Raffelhueschen, Social Health Insurance - the Major Driver of Unsustainable Fiscal Policy?, October 2005

1575 Roland Hodler and Kurt Schmidheiny, How Fiscal Decentralization Flattens Progressive Taxes, October 2005 
1576 George W. Evans, Seppo Honkapohja and Noah Williams, Generalized Stochastic Gradient Learning, October 2005

1577 Torben M. Andersen, Social Security and Longevity, October 2005

1578 Kai A. Konrad and Stergios Skaperdas, The Market for Protection and the Origin of the State, October 2005

1579 Jan K. Brueckner and Stuart S. Rosenthal, Gentrification and Neighborhood Housing Cycles: Will America’s Future Downtowns be Rich?, October 2005

1580 Elke J. Jahn and Wolfgang Ochel, Contracting Out Temporary Help Services in Germany, November 2005

1581 Astri Muren and Sten Nyberg, Young Liberals and Old Conservatives - Inequality, Mobility and Redistribution, November 2005

1582 Volker Nitsch, State Visits and International Trade, November 2005

1583 Alessandra Casella, Thomas Palfrey and Raymond Riezman, Minorities and Storable Votes, November 2005

1584 Sascha O. Becker, Introducing Time-to-Educate in a Job Search Model, November 2005

1585 Christos Kotsogiannis and Robert Schwager, On the Incentives to Experiment in Federations, November 2005

1586 Søren Bo Nielsen, Pascalis Raimondos-Møller and Guttorm Schjelderup, Centralized vs. De-centralized Multinationals and Taxes, November 2005

1587 Jan-Egbert Sturm and Barry Williams, What Determines Differences in Foreign Bank Efficiency? Australian Evidence, November 2005

1588 Steven Brakman and Charles van Marrewijk, Transfers, Non-Traded Goods, and Unemployment: An Analysis of the Keynes - Ohlin Debate, November 2005

1589 Kazuo Ogawa, Elmer Sterken and Ichiro Tokutsu, Bank Control and the Number of Bank Relations of Japanese Firms, November 2005

1590 Bruno Parigi and Loriana Pelizzon, Diversification and Ownership Concentration, November 2005

1591 Claude Crampes, Carole Haritchabalet and Bruno Jullien, Advertising, Competition and Entry in Media Industries, November 2005

1592 Johannes Becker and Clemens Fuest, Optimal Tax Policy when Firms are Internationally Mobile, November 2005

1593 Jim Malley, Apostolis Philippopoulos and Ulrich Woitek, Electoral Uncertainty, Fiscal Policy and Macroeconomic Fluctuations, November 2005 